Article

\title{
Experimental Evaluation and Modeling of the Damping Properties of Multi-Layer Coated Composites
}

\author{
Stefano Amadori *, Giuseppe Catania (1D) and Angelo Casagrande \\ Department of Industrial Engineering-Ciri MaM, University of Bologna, Viale Risorgimento 2, \\ 40136 Bologna, Italy; giuseppe.catania@unibo.it (G.C.); angelo.casagrande@unibo.it (A.C.) \\ * Correspondence: stefano.amadori4@unibo.it; Tel.: +39-051-209-3451
}

Received: 29 December 2017; Accepted: 26 January 2018; Published: 31 January 2018

\begin{abstract}
In this work, the dissipative properties of different coating solutions are compared and a beam mechanical model, taking into account of dissipative actions at the interface between different layers is proposed. The aim is to find optimal coatings to be employed in the production of composites with high damping properties. The investigated coating layers are obtained from different materials and production processes, and are applied on different metallic substrates. The composite specimens, in the form of slender beams, are tested by means of forced excitation dynamic measurements. Force and displacement experimental data, in a wide range of excitation frequencies, are used to estimate the system damping properties. Homogeneous, uncoated specimens are also tested for comparison. A specific identification procedure is used to identify the specimens stress-strain relationship in the frequency domain. The ratio of the imaginary part and the modulus of the specimen estimated complex frequency response function is considered as a measurement of the damping behaviour. A modified third order multi layered beam model, based on the zig-zag beam theory, is proposed. The model takes into account the contribution to the damping behaviour of the frictional actions and slipping at the interface between layers. Frictional actions are modelled by means of a complex, elasto-hysteretic contribution.
\end{abstract}

Keywords: hysteretic damping; coatings; dynamical measurement; multi-layer beam model; FGM

\section{Introduction}

Coating layer technologies are generally used to improve surface hardness, wear strength, thermal resistance, contact friction, with applications in the cutting tool and gas turbine industry [1-6]. Since mainly impulsive, high surface contact forces are expected to be applied to cutting tool components, coating toughness is a major requirement. Plasma Vapour Deposition (PVD) techniques and Chemical Vapour Deposition (CVD) techniques are mainly used in this context [3], generating high residual stresses at the interface between the coating layer and the substrate. In operating conditions, the combination of residual and working load generated stresses can produce coating peeling and surface cracks [2] that compromise the effectiveness of the coating treatment. Coating toughness and maximization of the coating adhesion properties are also a major requirement in other mechanical contexts such as Micro Electro-Mechanical Systems (MEMS) devices, where mainly large flexural displacements and strains, and by consequence high surface stresses, are expected [7]. Residual stress evaluation at the experimental and at the design stage is generally required in this context, and experimental nano-indentation techniques [8,9] and model-based techniques [7] are known.

Coatings can also be employed to increase the global dissipative properties of an industrial component with limited influence on the other mechanical properties [10-12]. Mechanical components with high stiffness, resistance and vibration damping specifications are in great demand for most 
aerospace, automotive and automation industrial mechanical applications, and some composite solutions are suitable to design components with these properties. In modern high-speed applications, unwanted vibrations may result due to high inertial forces. A vibrational response associated to a small displacement and deformation field but to a wide frequency range may cause an excessive noise level, a decrease in the system efficiency and a shortening of the system service life. By increasing the component dissipative properties, high vibration levels of the contact-free, external surface of thin walled mechanical components such as a mechanical pump, motor or gearing casing may be effectively damped.

Single or multiple layers of a coating material can be deposited or grown in order to produce a finished composite component with specifically designed characteristics including vibrational damping capability. Many different techniques are known [13,14] and in this work specimens obtained by means of the screen printing technology, mainly residual stress free, are compared.

The coating material structure [15-17], the interface structure [18], the temperature dependence [19] are all factors that must be taken into account when studying the influence of coatings on the coated component damping behaviour. The coated component dissipative properties can be significantly tailored by means of the application of coating layers showing high internal hysteresis or with high frictional actions at the interface between the different layers $[15,20,21]$. Experimental research done by these authors $[22,23]$ and other researchers $[13,24]$ outlined that the application of some coating surface solutions on thin-walled components can increase the vibration damping behaviour, and that this result is mainly due to dissipative actions originating at the interface between the substrate and the coating layer. It is known from literature that dynamic mechanical measurements are an effective experimental tool to study the damping behaviour of coated components and that both forced and free vibrations tests were employed to estimate the dissipative properties of a wide range of coating materials and component geometries by means of comparing the coated and uncoated component dynamical response [25-27]. In this work, the damping behaviour of different coating solutions applied on two different metal substrates, i.e., harmonic steel and $\mathrm{Al}$ alloy, are compared. Coated and uncoated specimen dynamic mechanical measurement test results are processed by means of a robust parameter identification and model condensation technique to investigate the effectiveness of the different solutions.

A multi layered beam model, taking into account the frictional actions localized at the interface between the layers, is proposed to help virtually test and find optimal coating solutions, to be applied to a mechanical system casing and to thin-walled components to be used in the high speed automation industry, in order to damp vibration and noise generated in working conditions. Dissipative actions are modeled by relaxing the kinematical displacement continuity at the layer interface and by introducing complex elasto-hysteretic dynamical interface coupling. The effects on the dissipative properties of the distributed constraints modeling boundary conditions are also taken into account. The model is based on zig-zag multi-layer beam theories [28-30], and on layer wise beam theories [31]. High order layer wise beam theories are obtained by modifying the classic Bernoulli-Euler and Timoshenko beam theories in order to deal with composite beams with numerous layers in which the mechanical and geometrical characteristics significantly vary from layer to layer. The advantage of zig-zag theories with respect to other layer wise theories is that the number of state space variables required by the model is low and does not depend on the number of layers. Since large residual stress free, amorphous based structure coatings, mainly deposited by screen printing technologies, are considered in this work, no account is given here with respect to experimental measuring and modeling of residual stresses generated at the interface between two different layers.

\section{Damping-Oriented Coating Solutions}

In this work three innovative, different coating solutions, applied to a slender beam, uniform rectangular cross section test specimen, are compared. Both homogeneous and composite specimens 
are taken into account. Two different types of metallic substrates are considered, harmonic steel (C67) and $\mathrm{Al}$ alloy (Al1000).

Three ceramic coating solutions are proposed, i.e., an alkali activated geopolymer (GP), an alkali activated alumina powder mixture (APM), an alkali activated zirconia powder mixture (ZPM). Ceramic materials, in comparison to metals and polymers, may present superior mechanical, chemical and thermal resistance properties [32].

\subsection{GP Solution}

The geopolymer solution is made by mixing of a commercial metakaolin powder (base) with an aqueous basis binder (activator) prepared from a potassium-hydroxide solution in $\mathrm{H}_{2} \mathrm{O}$ with pyrogenic silica solution. The chemical composition of the resulting solution is reported in Table 1.

Potassium was preferred to sodium in the alkaline activator since a better degree of polycondensation can be achieved and because of its ability to provide geopolymeric structures, associated with high mechanical strength [33]. Geopolymers are inorganic polymers formed by linear chains or tridimensional arrays of $\mathrm{SiO}_{4}$ and $\mathrm{AlO}_{4}$ tetrahedra [34]. The geopolymer is produced by mechanical mixing (planetary centrifugal mixer "Thiky Mixer" ARE 500 by THINKY, Tokyo, Japan) of a reactive powder base (Metakaolin Argical M 1200S, IMERYS, Cornwall, UK) with an aqueous basis activator $\left(\mathrm{H}_{2} \mathrm{O}\right.$ solution with potassium-hydroxide of $85 \%$ purity and an addition of a $99.8 \%$ purity pyrogenic silica solution). The prepared geopolymer has a $2.83 \mathrm{Si} / \mathrm{Al}$ ratio composition [34] and is applied to the upper and lower surfaces of the substrate beam by means of screen printing.

Table 1. GP composition.

\begin{tabular}{cccc}
\hline \multicolumn{2}{c}{ Base (Metakaolin) } & \multicolumn{2}{c}{ Activator } \\
\hline Components & Weight Fraction [\%] & Components & Molar Fraction \\
\hline $\mathrm{SiO}_{2}$ & 55 & $\mathrm{H}$ & \\
$\mathrm{Al}_{2} \mathrm{O}_{3} \mathrm{O}$ & 73.7 \\
\hline $\mathrm{K}_{2} \mathrm{O}+\mathrm{Na}_{2} \mathrm{O}$ & 39 & $\mathrm{KOH}$ & \multirow{2}{*}{11.7} \\
$\mathrm{Fe}_{2} \mathrm{O}_{3}$ & 1 & & \multirow{2}{*}{14.6} \\
\hline $\mathrm{TiO}_{2}$ & 1.8 & $\mathrm{SiO}_{2}$ & \\
$\mathrm{CaO}+\mathrm{MgO}$ & 1.5 & & \\
\hline
\end{tabular}

\subsection{APM and ZPM Solutions}

The APM solution is made by mixing of alumina powder, particle size $0.5 \mu \mathrm{m}$, with the activator defined in Table 1, mass ratio between alumina powder and activator being $1 / 1$. The ZPM solution is made by mixing of a zirconia powder, particle size $0.4 \mu \mathrm{m}$, with the activator defined in Table 1 , mass ratio between $\mathrm{Zr}$ powder and activator being 1/1.

The composite coatings result in a paste-like solution, and consolidation reactions then follow because of dehydration of the APM and ZPM solutions. Mechanical strength results from the chemical bonds between the basic potassium silicate in alkali solution chains and the acid alumina and zirconia powders.

\subsection{Specimens Preparation}

Eight composite components are obtained by applying coating layers on the two opposite faces of the beam substrate. The specimen geometry specifications are length $(11.0 \pm 0.01) \times 10^{-3} \mathrm{~m}$, thickness $(0.5 \pm 0.01) \times 10^{-3} \mathrm{~m}$ and width $(3.0 \pm 0.01) \times 10^{-3} \mathrm{~m}$.

Specimen data are reported in Table 2, including the specimen label, the substrate and the coating layer material, the production technique, and the coating layer thickness. Table 1 label "raw" indicates that the surface substrate is unfinished, texture $R_{\mathrm{a}} 0.8$, while "sdb" label refers to a sandblasted surface substrate, texture $R_{\mathrm{a}} 12$. After applying the GP, APM and ZPM coatings to the metal substrates, all samples were cured at $T=25^{\circ} \mathrm{C}$ for 9 days, in order to increase the adhesion behaviour [35]. 
Table 2. Specimen data.

\begin{tabular}{ccc}
\hline Specimen & Substrate & Coating Layer \\
\hline A1 & Al1000 (raw) & GP \\
A2 & Al1000 (sdb) & GP \\
A3 & Al1000 (raw) & APM \\
A4 & Al1000 (raw) & ZPM \\
S1 & Steel C67 (raw) & GP \\
S2 & Steel C67 (sdb) & GP \\
S3 & Steel C67 (raw) & APM \\
S4 & Steel C67 (raw) & ZPM \\
\hline
\end{tabular}

Note: the production technique is screen printing and the coating thickness is $125 \mu \mathrm{m}$.

According to known literature $[35,36]$, a geopolymer cured at room temperature tends to slowly change its structure and presents a low porosity and a high toughness while when cured at a higher temperature it exhibits faster structure changes, higher porosity and lower toughness.

In previous works [22,23], $\mathrm{TiO}_{2}$ and $\mathrm{Al}_{2} \mathrm{O}_{3}$ based coatings were considered, but the results did not show a meaningful improvement with respect to the uncoated beam specimen, concerning both vibration damping behaviour and adhesion strength in cyclic loading condition. In this contribution, new layer technologies based on a screen printing production process and inorganic polymer based composite material solutions, are taken into account.

\subsection{Optical and SEM Specimen Structural Characterization}

The coating structure and the coating-substrate interface is analyzed by means of optical and scanning electron microscopy (SEM). Samples were fracture cut in the transverse cross section, in order to expose the whole cross section. Before optical investigation, the specimen cross sections were embedded in epoxy resin and polished with abrasive $\mathrm{SiC}$ paper up to 2500 mesh and then by using a diamond based, $0.5 \mu \mathrm{m}$ particle size, lapping paste. Chemical etching (Ethanol added to $3 \% \mathrm{HNO}_{3}$ at $150{ }^{\circ} \mathrm{C}$ ) then follows.

Figure 1a-c report the SEM images related to the three coatings solutions proposed. All coatings present a typical composite structure, showing: geopolymer and unreacted potassium silicate (Figure 1a), the potassium silicate as matrix and fine alumina dispersed particles (Figure 1b), the potassium silicate as matrix and zirconia dispersed particles (Figure 1c). In Figure $1 \mathrm{~b}$ the $0.5 \mu \mathrm{m}$ particle size is observed and the almost total absence of shrinkage and solidification defects to form rigid structures, possibly associated to big strength characteristics, is also outlined. In Figure 1c, the size of zirconia powder is difficult to evaluate because of the resulting irregular morphology with brittle fragments of consolidate and dehydrate potassium silicate.

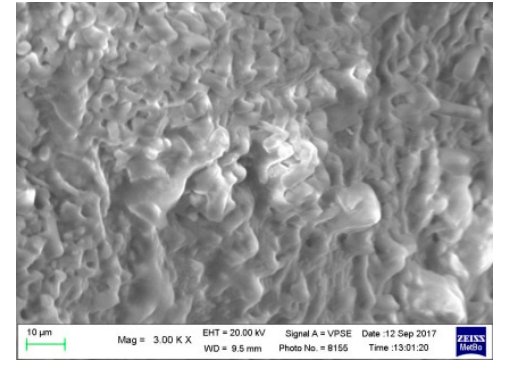

(a)

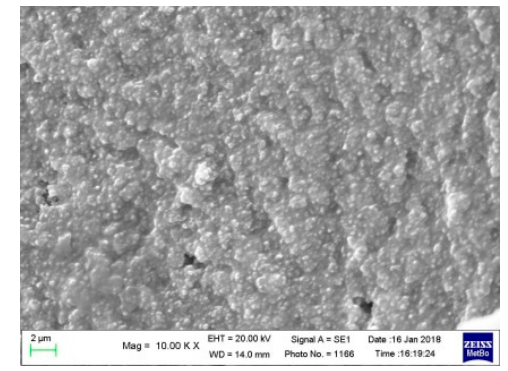

(b)

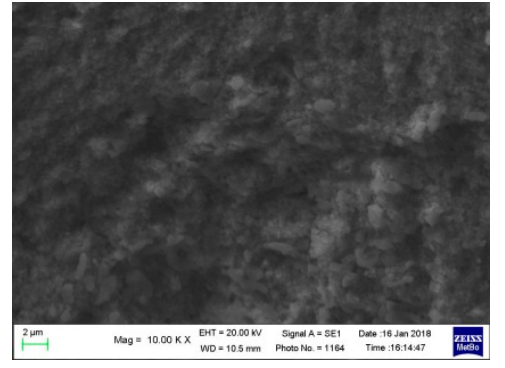

(c)

Figure 1. SEM images of the different coating solutions fracture structure: (a) GP; (b) APM; (c) ZPM.

Figure 1a, referring to the geopolymeric coating, shows a compacted interconnected microstructure which can increase toughness and strength in comparison to the other coatings considered. The 
amorphous nature of these coatings may greatly influence the stress state of consolidate coatings, so that there are no detectable cracks and microcracks that could compromise the performance of the coatings when subjected to mechanical strain vibrations, because no differences induced by thermal and mechanical stresses into the polycrystalline state are expected to appear in working conditions.

Figure $2 \mathrm{a}-\mathrm{f}$ report the optical images related to the interface obtained by means of the three coatings solutions and two metal substrates investigated. As shown, there is an evident adhesion between ceramic coatings and the metal substrate.

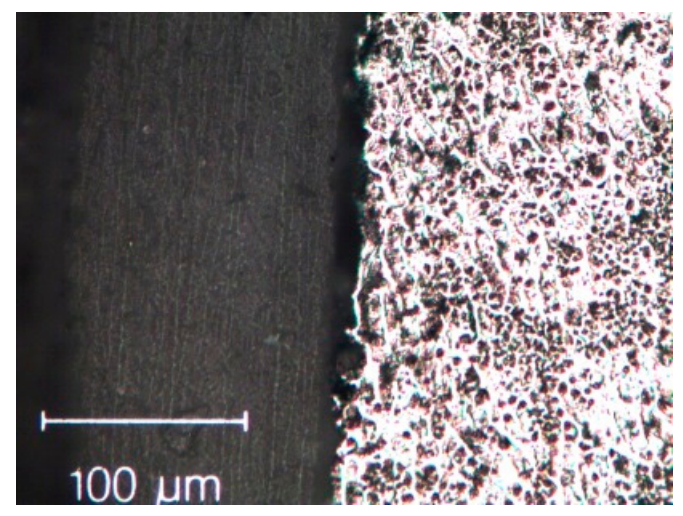

(a)

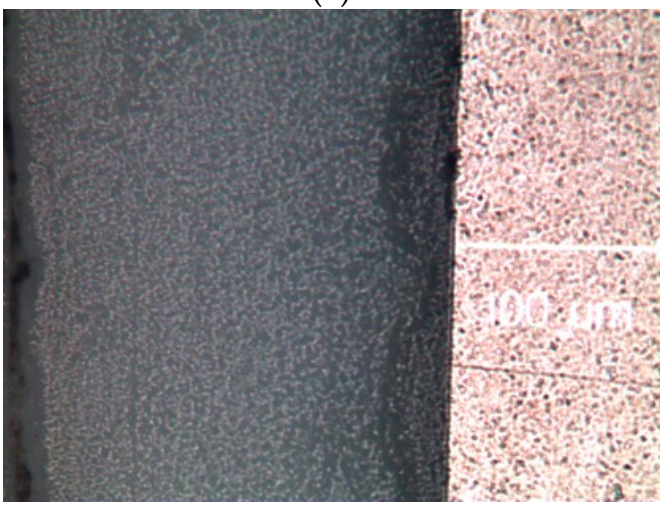

(c)

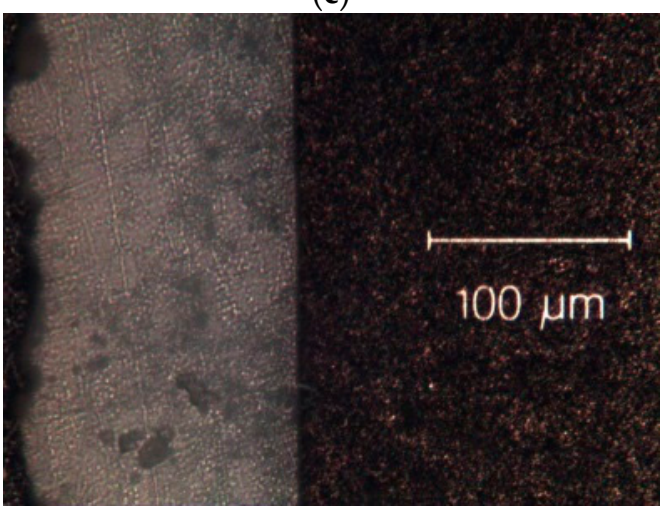

(e)

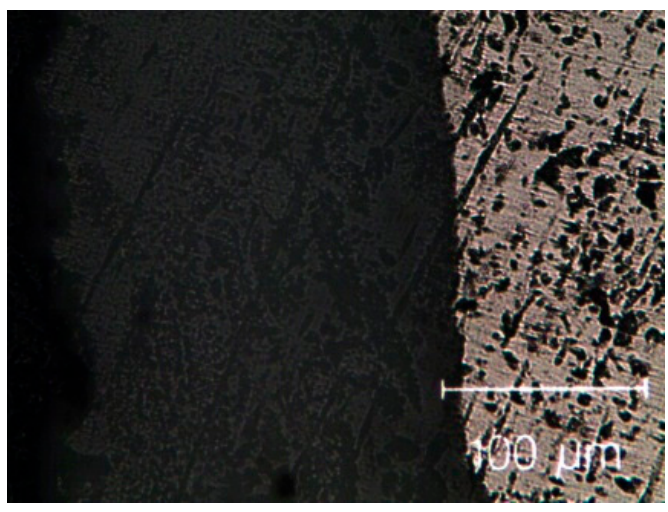

(b)

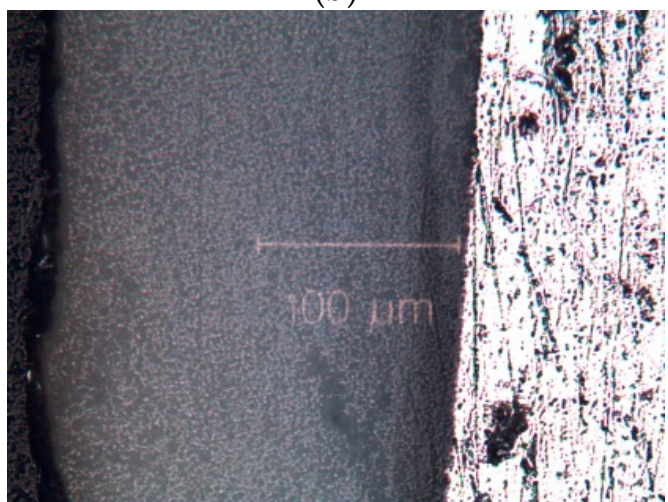

(d)

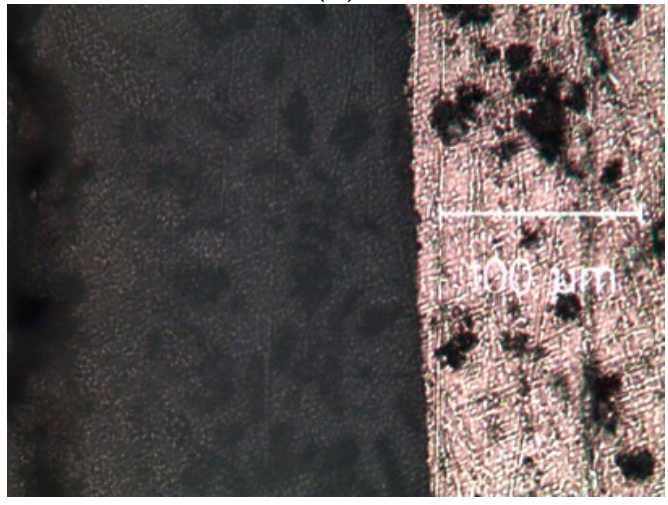

(f)

Figure 2. Optical micrograph images $(200 \times)$ of the interface between coating (left) and metal substrate (right): (a) GP/C67; (b) GP/Al1000; (c) APM/C67; (d) APM/Al1000; (e) ZPM/C67; (f) ZPM/Al1000.

Figure 3a-f report the SEM images related to the interface obtained by means of the three coatings solutions and two metal substrates investigated. Defects by shrinkage phenomena at the metal coating 
interface are not shown. It can be outlined that the adhesion between the proposed coating solutions and the Al1000 substrate appears to be more effective than with respect to the C67 substrate.

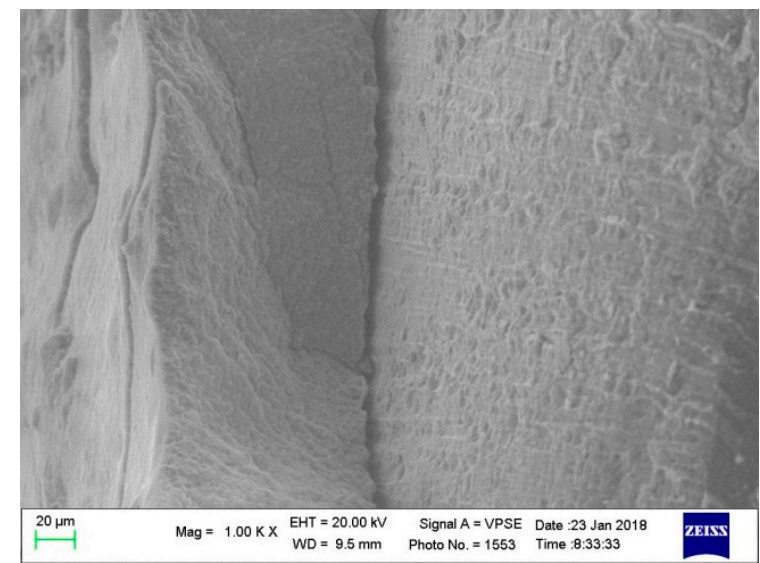

(a)

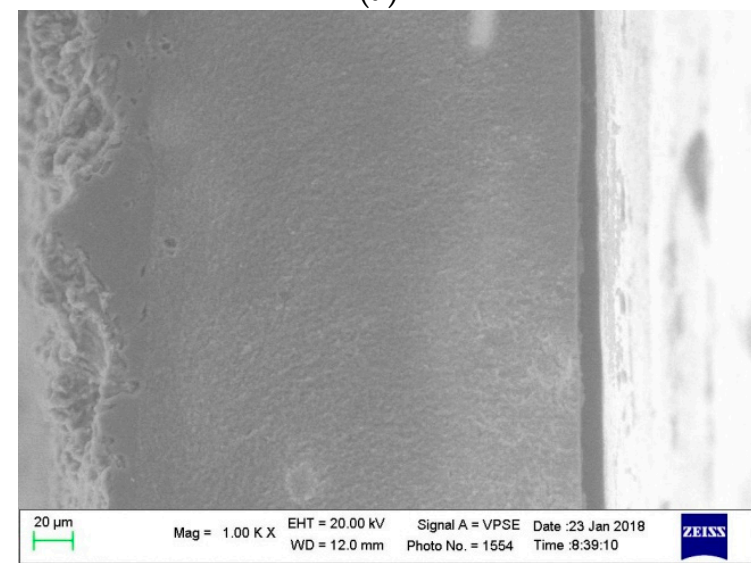

(c)

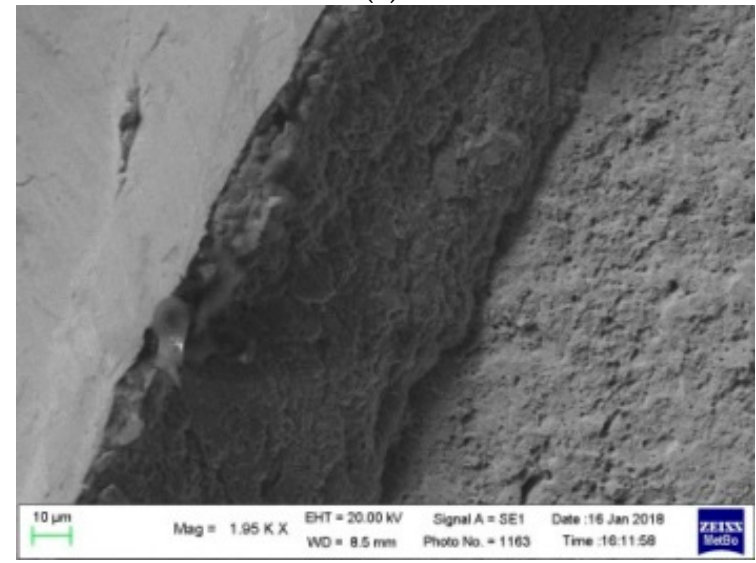

(e)

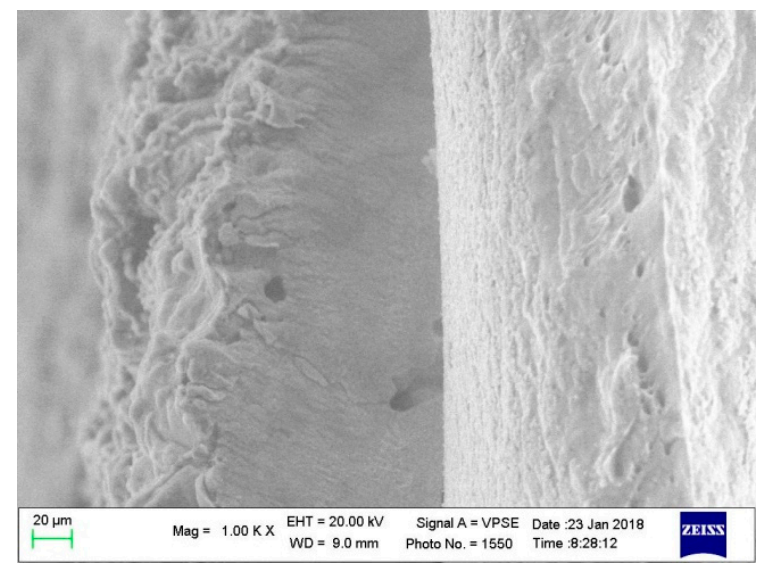

(b)

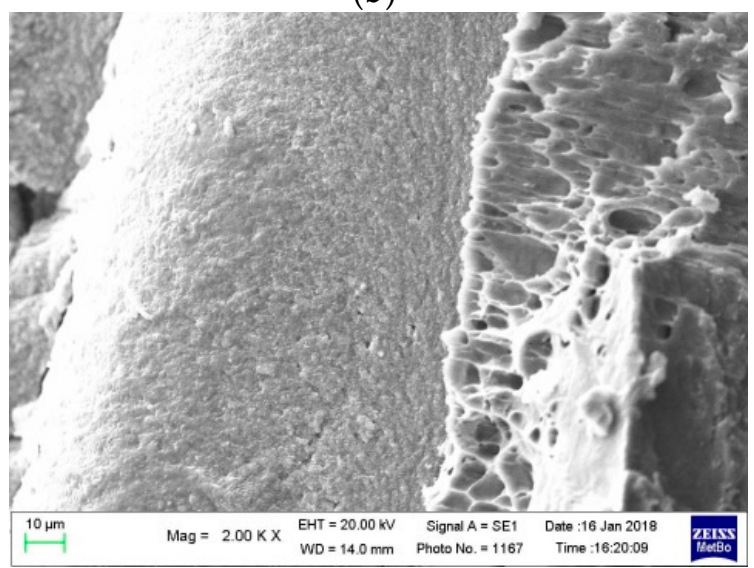

(d)

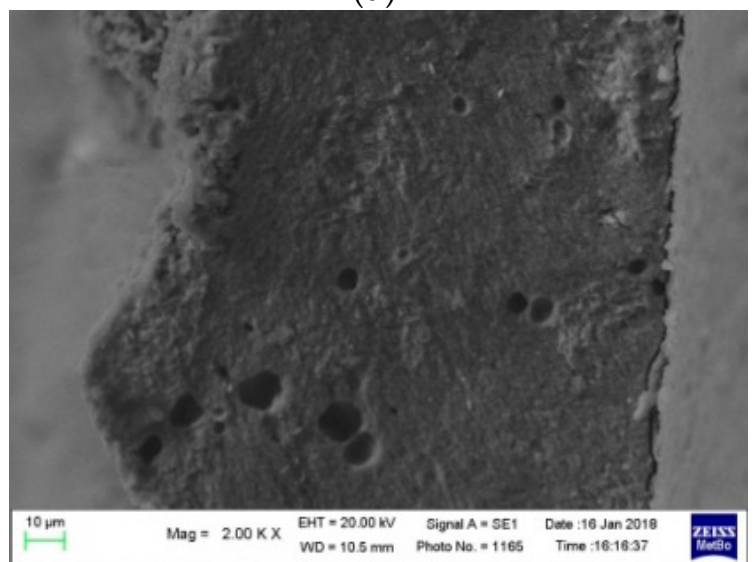

(f)

Figure 3. SEM images of the of the interface between coating (left) and metal substrate (right): (a) GP/C67; (b) GP/Al1000; (c) APM/C67; (d) APM/Al1000; (e) ZPM/C67; (f) ZPM/Al1000.

\section{Identification Procedure}

In this work, applied force and displacement data obtained by means of dynamic mechanical measurements over a wide frequency range are used to estimate the complex modulus $E(\omega)$ of 
measured beam specimens. The values of $E(j \omega)$ are estimated by means of a procedure fully defined by the authors of this work in a previous paper [29] and are here briefly outlined.

$E(j \omega)$ defines the specimen stress $(\hat{\sigma})$-strain $(\hat{\varepsilon})$ equivalent material relationship in the frequency domain (Equation (1)):

$$
\hat{\sigma}=E(j \times \omega) \times \hat{\varepsilon}
$$

Slender beams of uniform rectangular cross section with clamped sliding boundary conditions are considered. The contribution of the inertial actions is also taken into account.

The complex, experimentally estimated values of $E_{i}=E\left(\omega_{i}\right)$ at frequencies $\omega_{i}$ are found by finding the solutions of Equation (2) by means of the Newton Raphson method, starting from known static modulus $E_{0}=E(j \omega=0)$ :

$$
\Theta\left(E_{i}\right)=\sum_{s=1}^{n_{m}} \frac{\left[\frac{2 \times \sinh k_{s} \times \sin k_{s}}{\cosh k_{s}+\cos k_{s}}\right]^{2}}{E\left(j \times \omega_{i}\right) \times k_{s}^{4} \times I / L^{3}-M \times \omega_{i}^{2}}-\frac{\hat{v}\left(j \times \omega_{i}\right)}{\hat{q}\left(j \times \omega_{i}\right)}=0
$$

$\hat{v}\left(j \omega_{i}\right)$ and $\hat{q}\left(j \omega_{i}\right)$ are respectively the measured transverse displacement and applied periodic force (at frequency $\omega_{i}$ ) at the beam sliding end. $M$ is the beam mass, $I$ is the beam section moment, $L$ is the beam length and $k_{s}$ are the roots of $f\left(k_{s}\right)=\tan \left(k_{s}\right)+\tanh \left(k_{s}\right)=0$.

A specific robust identification and condensation procedure [37] is applied on the $E(j \omega)$ experimentally estimated values to identify the specimens stress-strain relationship in the frequency domain. $E(j \omega)$ (Equation (1)) is modeled by means of a high order generalized Kelvin model and its parameters are identified. The global model order can be condensed to obtain a new model of comparable accuracy but significantly lower order.

\section{Experimental Set-Up, Measurement and Discussion}

\subsection{Experimental Set-Up}

The dynamic mechanical tests are realized with a standard dynamic mechanical analyzer apparatus (TA Instrument DMA Q800, New Castle, DE, USA) in a forced flexural excitation, harmonic sine, experimental set up Figure 4, clamped sliding boundary conditions, $0.01 \%$ maximum strain, 0.01-200 Hz frequency range with minimal frequency resolution $\Delta f=0.01 \mathrm{~Hz}$ and air flow $35^{\circ} \mathrm{C}$ isothermal conditions. Transverse displacement and applied periodic force amplitude, at frequency $\omega_{i}$, are measured at the beam sliding end.

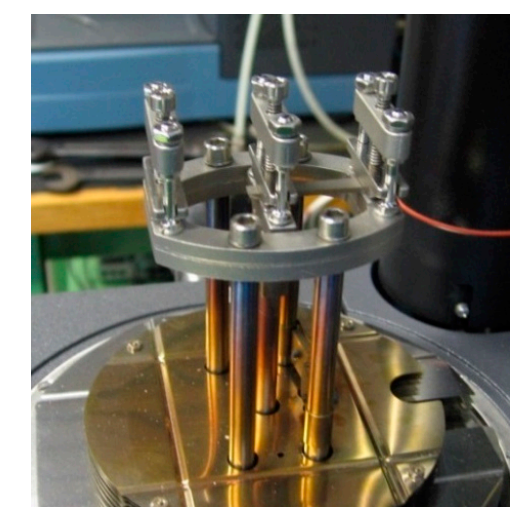

(a)

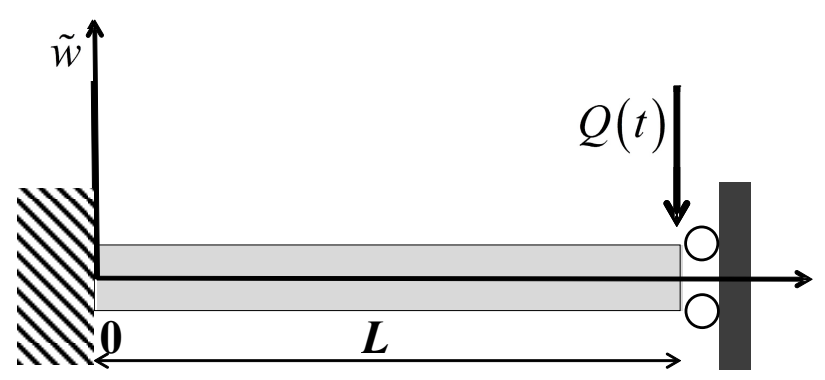

(b)

Figure 4. (a) DMA single-cantilever flexural experimental set up with specimen; (b) Schematic representation of a slender beam in the single-cantilever experimental set-up. 
The experimentally $E(j \omega)$ estimated values are obtained by means of the procedure reported in Section 3. The specimen dissipative properties are estimated by $z(j \omega)=\operatorname{Im}(E) /|E|$, a normalized real coefficient belonging to the $[0,1]$ range, so that being it different with respect to the standard approach based on $\tan \delta=\operatorname{Im}(E) / \operatorname{Re}(E)$ choice [38] and meaningful when used to compare different solutions. The results obtained for the homogeneous and the composite specimens are compared and shown in Figures 5-8.

\subsection{Experimental Results and Discussion}

The results obtained for specimens coated with GP (A1, A2, S1 and S2), reported in Figures 5 and 6 , show a general increase of the damping properties with respect to the uncoated specimens. The damping increase appears to depend on the type of the substrate and the surface texturing.

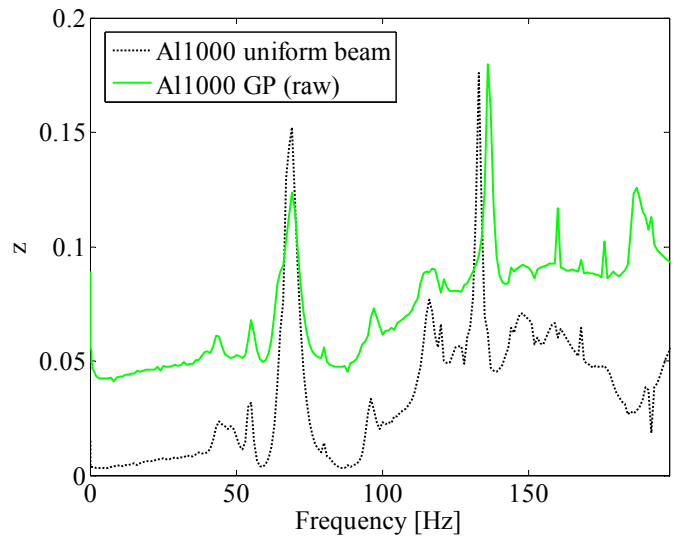

(a)

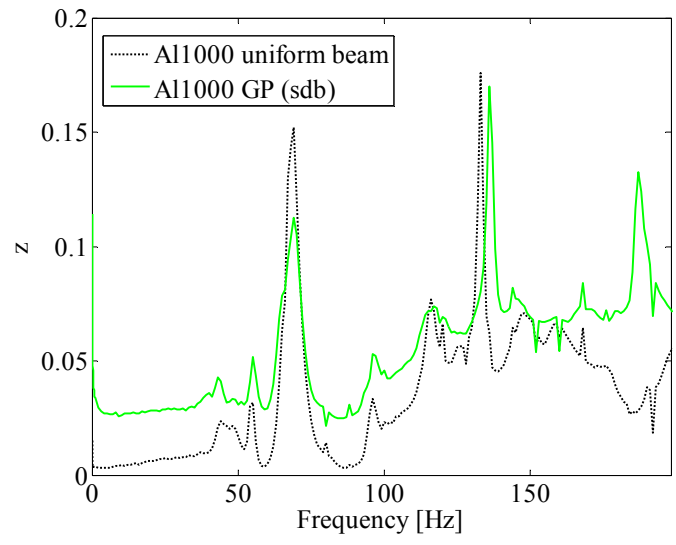

(b)

Figure 5. $z(j \omega)$ estimates for A1 (a) and A2 (b) specimen and homogeneous Al1000 specimen.

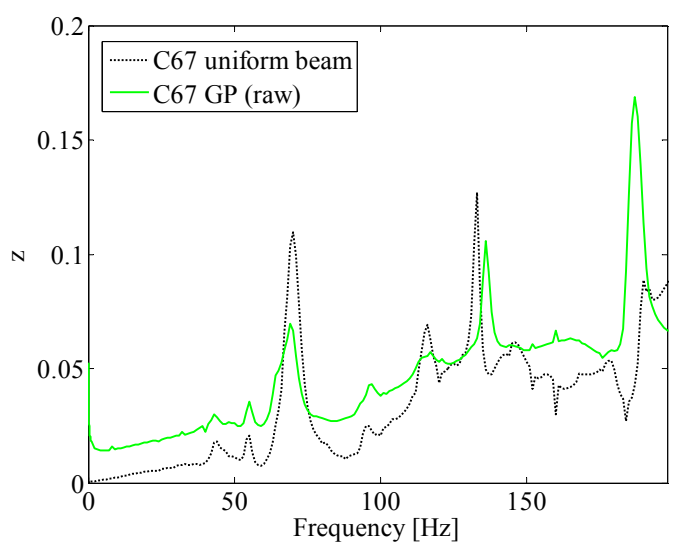

(a)

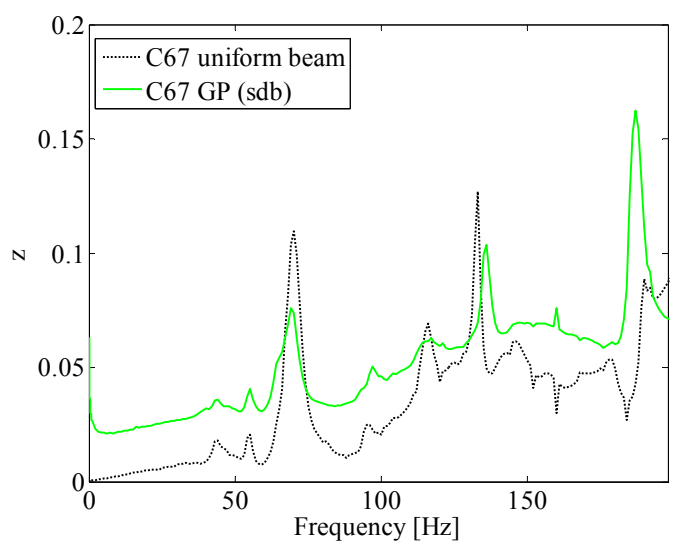

(b)

Figure 6. $z(j \omega)$ estimates for S1 (a) and S2 (b) specimen and homogeneous C67 specimen. 


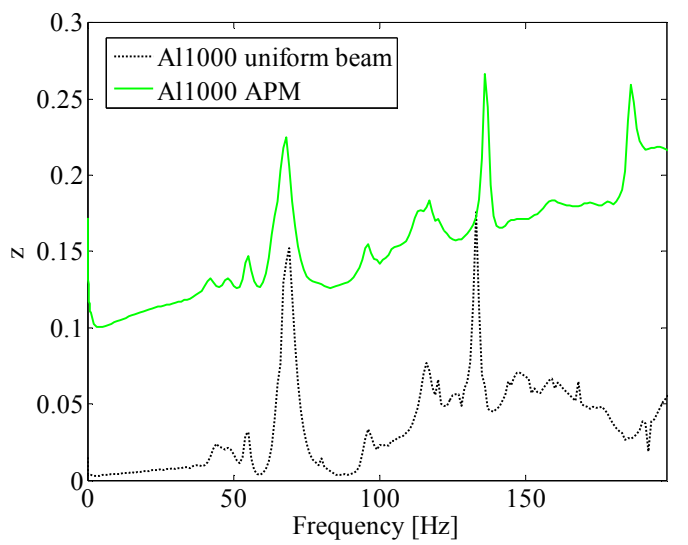

(a)

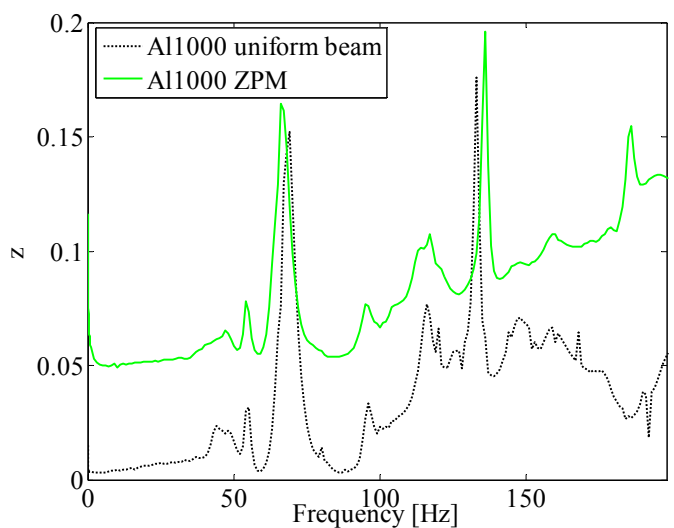

(b)

Figure 7. $z(j \omega)$ estimates for A3 (a) and A4 (b) specimen and homogeneous Al1000 specimen.

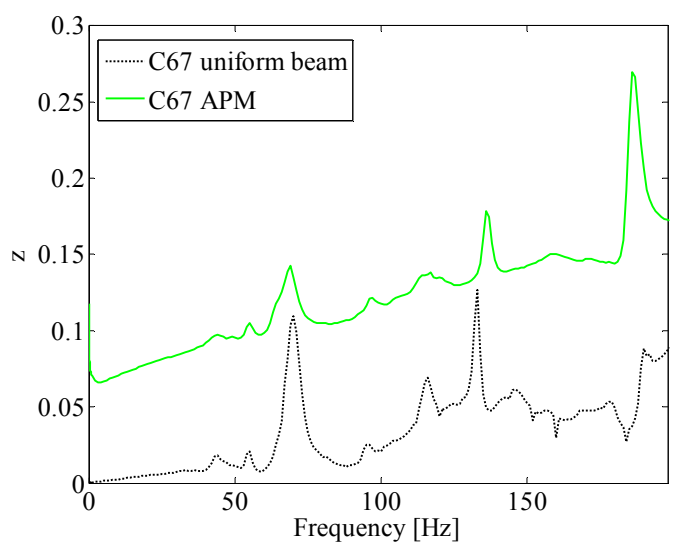

(a)

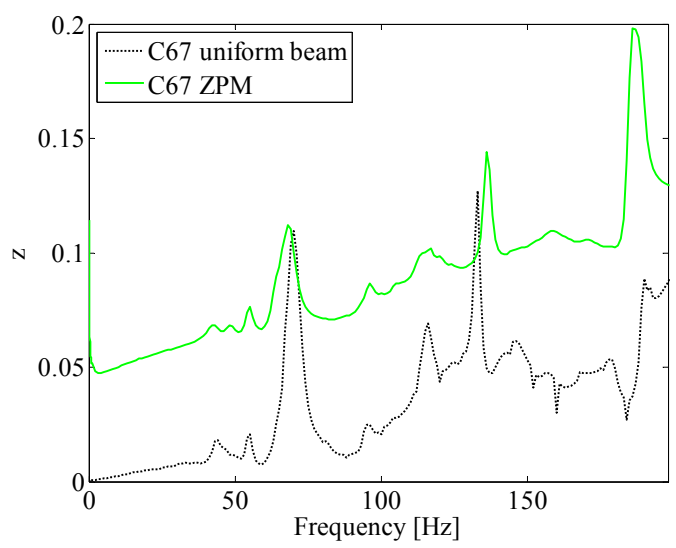

(b)

Figure 8. $z(j \omega)$ estimates for S3 (a) and S4 (b) specimen and homogeneous C67 specimen.

The A1 specimen shows the largest $z(j \omega)$ increase, A2 and S2 specimens show a similar increase of $z(\omega)$, while S1 component shows to be the less effective solution of this set. The results obtained from specimens A3, A4, S3 and S4 (APM, ZPM) are plotted in Figures 7 and 8, showing the greatest improvement in damping behavior. As in the previous case, the effectiveness of the coating solution is also dependent on the substrate material, since both the APM (A3, S3) and ZPM (A4, S4) composite solutions appear to be more effective on Al1000 than on C67 substrate.

Coating solutions adopted in specimens A1-4 and S1-4 can be considered more effective than other solutions previously investigated by the authors of this work $[22,23]$ and other researchers in the same field (in the authors' knowledge).

Figure 9 shows the $z(j \omega)$ ratio estimate with respect to homogeneous specimens made with the GP, APM and ZPM coating materials. The three coating materials exhibit good damping capabilities, with the GP specimen displaying the lower $z(j \omega)$ ratio and the ZPM specimen being associated to the most effective solution. Figures 5-8 indicate that the damping behaviour is strongly influenced by the dissipative actions (friction) exhibited at the interface between composite substrate and the coating layer, thus dominating the effect of the internal dissipative actions of the coating material. In Figures 5 and 6 , same substrate and coating layers but different substrate surface texture influences the damping behaviour, while in Figures 7 and 8, while there is the same coating and surface texture, the damping behaviour is influenced by the substrate material. It appears that $\mathrm{A} 3$ is the most effective solution of the evaluated set, and the APM coating is less effective than ZPM from the inherent material 
standpoint (Figure 9), so that enforcing the assumption that dissipative actions mainly depend on the interlaminar interface structure and do not depend on the distributed material coating properties. Figure 10a shows a condensed global model of order $n=13$ for the A3 specimen and Figure 10b shows a condensed global model of order $n=14$ for the S3 specimen. In both cases an identified global model of significantly higher order $(n=43)$ is initially obtained and then processed by means of the condensation procedure and of the evaluation and processing of pole stability diagrams.

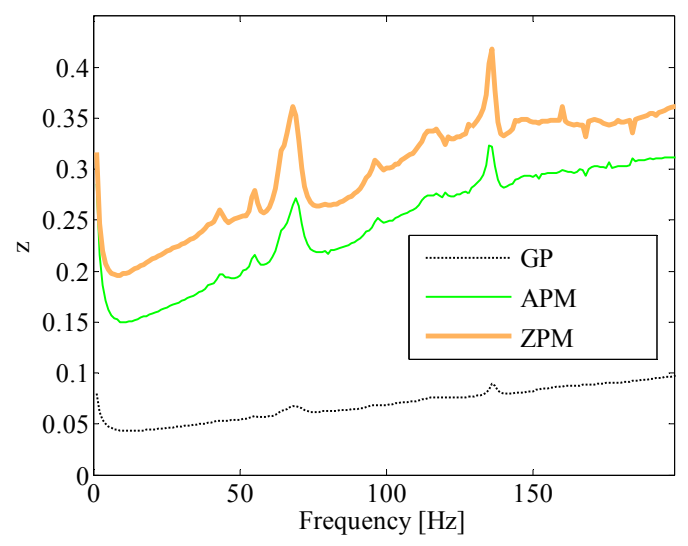

Figure 9. $z(j \omega)$ estimates for homogeneous specimens of GP, APM and ZPM.
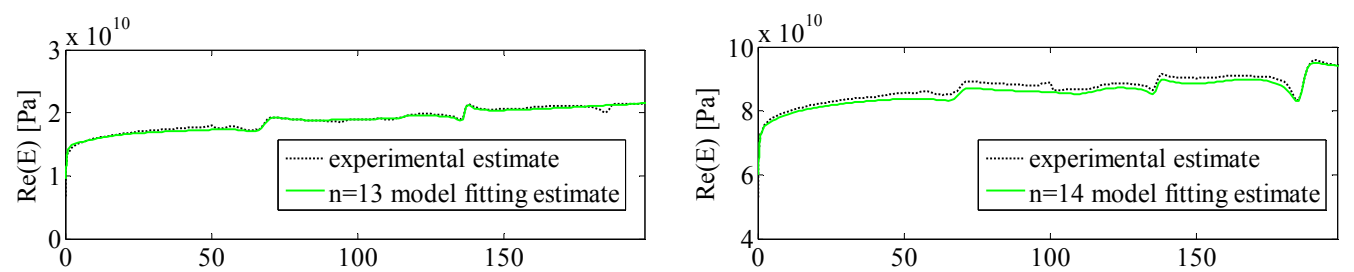

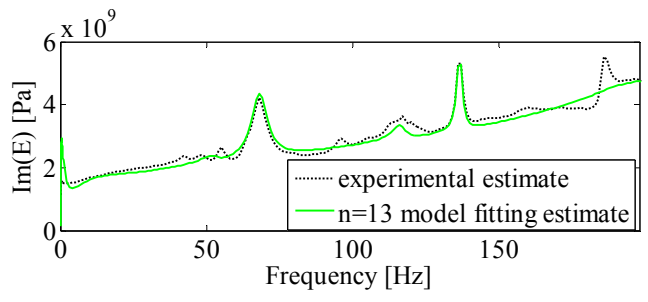

(a)

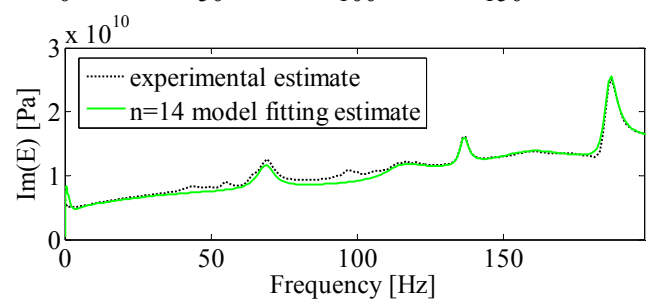

(b)

Figure 10. (a) A4 specimen $E(\omega)$ experimental estimate versus $n=13$ condensed model fitting estimate; (b) S4 specimen $E(\omega)$ experimental estimate versus $n=14$ condensed model fitting estimate.

\section{Modeling of Multi-Layer Coated Beam Composites}

\subsection{Motivations}

The contribution of interface dissipative actions to the damping behaviour of coated components is clearly outlined from the results presented in the previous sections. Nevertheless, while the procedure used to obtain the condensed, generalized standard linear solid model $E(j \omega)$ may be indeed effective to estimate the damping properties of different specimens and to compare them, it cannot be used to design and predict the damping behaviour of new, not previously tested, coating solutions. An effective model must be able to take into account the coating solution architecture, i.e., the number of layers, the thickness, the material and the coating technology adopted for the different layers as well.

In literature many models are known for multi-layered beams and plates [29,39-44] but no attempts can be found with respect to modelling the interface dissipative actions. In this section, 
a multi-layered beam model based on zig-zag beam and plates theory addressing this issue is presented. The model takes into account the layers of geometric and material properties and is able to deal with interface slipping and local friction. The model uses an elasto-hysteretic contribution to define the dissipative actions at the interface between the layers.

\subsection{Multi-Layer Beam Flexural Model}

A schematic representation of a multi-layered beam model is reported in Figure 11. A multi-layered beam made up of $N$ layers and with uniform rectangular section is considered. $L, g, h$, are respectively the beam length, width and thickness, $V=L \times g \times h, \rho_{i}$ is the $i$-th layer density. In each layer $(i=1, \ldots, N)$, the material constitutive equations are assumed to be:

$$
\sigma\left(\lambda \in\left[\lambda_{i-1}, \lambda_{i}\right]\right)=E_{i} \times \varepsilon, \tau\left(\lambda \in\left[\lambda_{i-1}, \lambda_{i}\right]\right)=G_{i} \times \gamma, i=1, \ldots, N
$$

where $E_{i}$ and $G_{i}$ are the $i$-th layer longitudinal and shear elastic moduli, $\sigma=\sigma_{x x}$ and $\tau=\tau_{x y}$ are the flexural stress and shear stress components, $\varepsilon=\varepsilon_{x x}$ and $\gamma=\gamma_{x y}$ are the strain components. Since small displacement and deformation fields are considered, transverse displacement $\widetilde{w}$ is assumed as being stationary with respect to $y, \lambda$. Transverse and longitudinal displacement $\widetilde{w}, \widetilde{u}$ are assumed as follows:

$$
\begin{aligned}
& \widetilde{w}=L \times w(\chi, t), \widetilde{u}=h \times u(\chi, \lambda, t) \\
& u(\chi, \lambda, t)=a+b \times \lambda+c \times \lambda^{2}+d \times \lambda^{3}, 0 \leq \lambda \leq \lambda_{1} \\
& u(\chi, \lambda, t)=a+b \times \lambda+c \times \lambda^{2}+d \times \lambda^{3}+\left(a_{i}+b_{i} \times \lambda\right), \lambda_{i-1} \leq \lambda \leq \lambda_{i}, i=2 \ldots N
\end{aligned}
$$

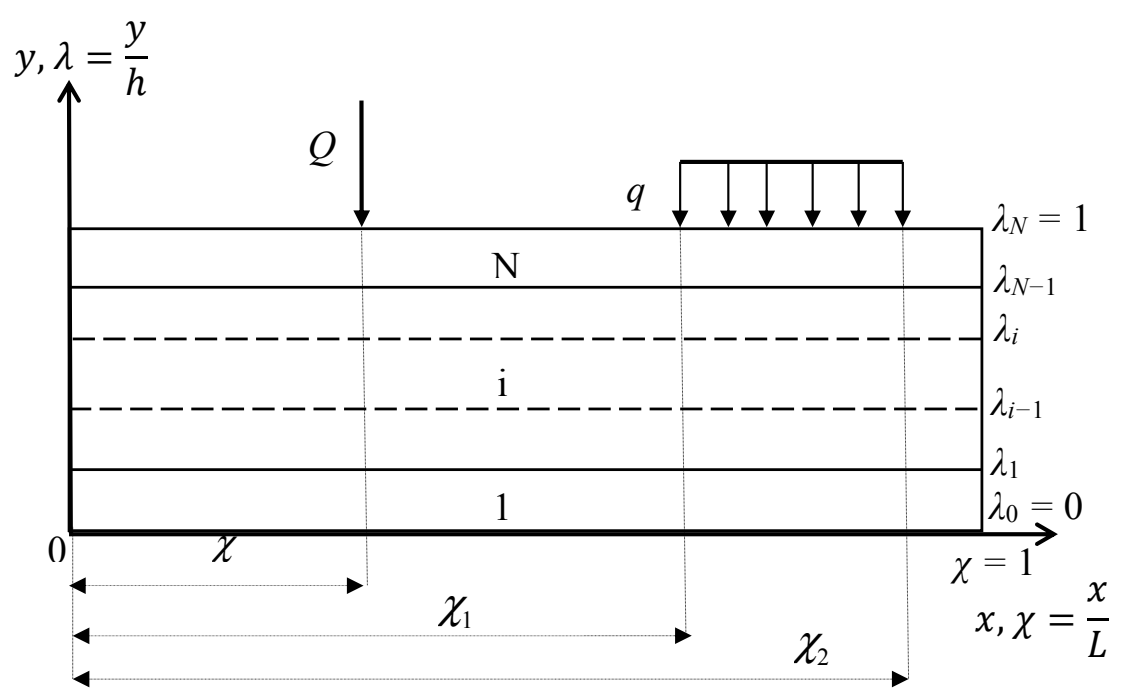

Figure 11. Multi-layer beam model schematic representation.

The following $2 \times N+3$ state variables result:

$$
\left\{\begin{array}{llllllllll}
w(\chi, t) & a(\chi, t) & b(\chi, t) & c(\chi, t) & d(\chi, t) & a_{2}(\chi, t) & b_{2}(\chi, t) & \ldots & a_{N}(\chi, t) & b_{N}(\chi, t)
\end{array}\right\}^{T}
$$

The kinematical relationships between strain and displacement components is assumed to be:

$$
\begin{aligned}
& \varepsilon(\chi, \lambda, t)=\frac{h}{L} \times u^{\prime} \\
& \gamma(\chi, \lambda, t)=w^{\prime}+b+2 \times c \times \lambda+3 \times d \times \lambda^{2}, \quad \lambda \leq \lambda_{1} \\
& \gamma(\chi, \lambda, t)=\frac{\partial u}{\partial \lambda}+w^{\prime}=w^{\prime}+b+b_{i}+2 \times c \times \lambda+3 \times d \times \lambda^{2}, \quad \lambda_{i-1} \leq \lambda \leq \lambda_{i}
\end{aligned}
$$

where ()$^{\prime}=\partial() / \partial \chi=L \times \partial() / \partial x$. 
$N+1$ equilibrium conditions at the layer interfaces hold:

$$
\begin{gathered}
\tau(0)=G_{1} \times \gamma(0)=0, \tau(1)=G_{N} \times \gamma(1)=0 \\
\tau\left(\left(\lambda_{i}\right)^{-}\right)=G_{i} \times \gamma\left(\left(\lambda_{i}\right)^{-}\right)=G_{i+1} \times \gamma\left(\left(\lambda_{i}\right)^{+}\right)=\tau\left(\left(\lambda_{i}\right)^{+}\right), \quad i=1, \ldots, N-1
\end{gathered}
$$

where ()$^{-}=\lim _{\Delta \rightarrow 0}(()-\Delta),()^{+}=\lim _{\Delta \rightarrow 0}(()+\Delta)$

From Equation (7):

$$
b=-w^{\prime}, b_{N}=-2 \times c-3 \times d
$$

From Equations (6), (8) and (9), a system of $N-1$ equations can be obtained:

$$
\left\{\begin{array}{l}
G_{2} \times b_{2}=\left(3 \times d \times \lambda_{1}^{2}+2 \times c \times \lambda_{1}\right) \times\left(G_{1}-G_{2}\right) \\
\cdots \\
G_{N} \times b_{N}-G_{k} \times b_{N-1}=\left(3 \times d \times \lambda_{N-1}^{2}+2 \times c \times \lambda_{N}\right) \times\left(G_{N-1}-G_{N}\right)
\end{array}\right.
$$

By equating the Equation (10) right side sum to Equation (10) left side sum, and taking into account of Equation (9):

$$
c=\bar{c} \times d, \quad \bar{c}=-\frac{3}{2} \times \bar{\lambda}, \quad \bar{\lambda}=\frac{\left\{\sum_{i=1}^{N-1}\left[\lambda_{i}^{2} \times\left(G_{i}-G_{i+1}\right)\right]+G_{N}\right\}}{\left\{\sum_{i=1}^{N-1}\left[\lambda_{i} \times\left(G_{i}-G_{i+1}\right)\right]+G_{N}\right\}}
$$

$c$ is a stationary value defined by the shear moduli and thickness values of the beam layers. By defining the following variable change:

$$
b_{i}=\bar{b}_{i} \times d, \quad i=2 \ldots N
$$

Putting Equations (10)-(12), the following iterative formula results:

$$
\begin{aligned}
& \bar{b}_{2}=3 \times \lambda_{1} \times \frac{G_{1}-G_{2}}{G_{2}} \times\left(\lambda_{1}-\bar{\lambda}\right) \\
& \bar{b}_{i+1}=\frac{G_{i}}{G_{i+1}} \times \bar{b}_{i}+3 \times \lambda_{i} \times \frac{G_{i}-G_{i+1}}{G_{i+1}} \times\left(\lambda_{i}-\bar{\lambda}\right) \quad i=2 \ldots N-1
\end{aligned}
$$

Now by relaxing the continuity of the kinematical $u$ component at $\lambda=\lambda_{i}$ interface, the longitudinal sliding $v(\lambda)=u\left((\lambda)^{+}\right)-u\left((\lambda)^{-}\right)$at the interface is:

$$
\begin{aligned}
& v\left(\lambda_{1}, \chi, t\right)=v_{1}(\chi, t)=\left(\bar{b}_{2} \times \lambda_{1} \times d+a_{2}\right) \\
& v\left(\lambda_{i}, \chi, t\right)=v_{i}(\chi, t)=\left(\left(\bar{b}_{i+1}-\bar{b}_{i}\right) \times \lambda_{i} \times d+a_{i+1}-a_{i}\right), \quad i=2, \ldots, N-1
\end{aligned}
$$

At $\lambda=\lambda_{i}$ interface, an elasto-hysteretic constitutive relationship is assumed by means of complex impedance $\Phi_{i}$ :

$$
\tau\left(\lambda_{i}\right)=\Phi_{i} \times h \times v_{i}(\chi, t), \Phi_{i}=\varphi_{i}+j \times \eta_{i}, \quad \Omega_{i}=\Phi_{i}^{-1}=\frac{\varphi_{i}-j \times \eta_{i}}{\left|\Phi_{i}\right|^{2}} ; \quad i=1, \ldots, N-1
$$

where $j=\sqrt{-1}$. Defining the following variable change:

$$
a_{i}=\bar{a}_{i} \times d, \quad i=2 \ldots N
$$


the values of $a_{i}$ from the following iterative formula, obtained by combining Equations (3), (14) and (15):

$$
\begin{aligned}
& \bar{a}_{2}=-3 \times\left(\lambda_{1}-\bar{\lambda}\right) \times \lambda_{1} \times\left(\frac{\Omega_{1} \times G_{1}}{h}+\frac{G_{1}-G_{2}}{G_{2}}\right) \\
& \bar{a}_{i+1}=\bar{a}_{i}-\left(\bar{b}_{i+1}-\bar{b}_{i}\right) \times \lambda_{i}+\frac{\Omega_{i} \times G_{i}}{h} \times\left(3 \times\left(\lambda_{i}-\bar{\lambda}\right) \times \lambda_{i}+\bar{b}_{i}\right), \quad i=2, \ldots, N-1
\end{aligned}
$$

From Equations (11), (13) and (17), stationary $\bar{a}_{i}, \bar{b}_{i}, \bar{c}$, values result. Only three independent state variables, collected in vector $\mathbf{X}$, result:

$$
\mathbf{X}=\mathbf{X}(\chi, t)=\left\{\begin{array}{lll}
w(\chi, t) & a(\chi, t) & d(\chi, t)
\end{array}\right\}^{T}
$$

The following expression of the kinematical components result:

$$
\begin{gathered}
w=\left[\begin{array}{lll}
0 & 1 & 0
\end{array}\right] \times \mathbf{X}, \quad u=\left[\begin{array}{ccc}
1 & -\lambda & \theta(\lambda)
\end{array}\right] \times\left[\begin{array}{ccc}
1 & 0 & 0 \\
0 & ()^{\prime} & 0 \\
0 & 0 & 1
\end{array}\right] \times \mathbf{X} \\
\varepsilon=\frac{h}{L} \times\left[\begin{array}{lll}
1 & -\lambda & \theta(\lambda)
\end{array}\right] \times\left[\begin{array}{ccc}
()^{\prime} & 0 & 0 \\
0 & ()^{\prime \prime} & 0 \\
0 & 0 & ()^{\prime}
\end{array}\right] \times \mathbf{X}, \quad \gamma=\frac{\partial \theta(\lambda)}{\partial \lambda} \times\left[\begin{array}{lll}
0 & 0 & 0 \\
0 & 0 & 0 \\
0 & 0 & 1
\end{array}\right] \times \mathbf{X} \\
\theta\left(\lambda \leq \lambda_{1}\right)=\left(\lambda-\frac{3}{2} \times \bar{\lambda}\right) \times \lambda^{2} \\
\theta\left(\lambda_{k-1} \leq \lambda \leq \lambda_{k}\right)=\left(\lambda-\frac{3}{2} \times \bar{\lambda}\right) \times \lambda^{2}+\bar{b}_{i} \times \lambda+\bar{a}_{i}
\end{gathered}
$$

\subsection{Equation of Motion}

To obtain the equation of motion, the system total potential energy $(\Pi)$ is considered:

$$
\Pi=U+W_{I}+W_{E}+\Delta \Pi
$$

$U$ is the contribution of the internal elasto-hysteretic actions:

$$
U=\frac{V}{2} \times\left(\int_{0}^{1} \int_{0}^{1} \sigma \times \varepsilon \times d \lambda \times d \chi+\int_{0}^{1} \int_{0}^{1} \tau \times \gamma \times d \lambda \times d \chi\right)
$$

$W_{I}$ is the contribution of the inertial actions:

$$
W_{I}=V \times\left(h^{2} \times \int_{0}^{1} \int_{0}^{1} \rho \times u \times \ddot{u} \times d \lambda \times d \chi+L^{2} \times \int_{0}^{1} \int_{0}^{1} \rho \times w \times \ddot{w} \times d \lambda \times d \chi\right)
$$

where $(j)=\partial^{2}() / \partial t^{2} \cdot W_{E}$ is the contribution of the external forces:

$$
W_{E}=-Q \times L \times w(\bar{\chi})-L^{2} \times g \times \int_{\chi_{1}}^{\chi_{2}} q(\chi) \times w \times d \chi
$$

where $Q$ is a lumped force applied at $\bar{\chi}$ and $q$ is a distributed pressure applied at $\chi_{1} \leq \chi \leq \chi_{2}$. 
$\Delta \Pi$ is the contribution of the distributed, viscous elastic, constraints modeling boundary conditions:

$$
\begin{aligned}
& \Delta \Pi=\Delta \Pi_{e}+\Delta \Pi_{v} \\
& \Delta \Pi_{e}=\frac{V}{2} \times\left(L^{2} \times \int_{0}^{1} K_{w}(\chi) \times w \times w \times d \chi+h^{2} \times \int_{0}^{1} \int_{0}^{1} K_{u}(\chi, \lambda) \times u \times u \times d \lambda \times d \chi\right. \\
& \Delta \Pi_{v}=V \times\left(L^{2} \times \int_{0}^{1} C_{w}(\chi) \times w \times \dot{w} \times d \chi+h^{2} \times \int_{0}^{1} \int_{0}^{1} C_{u}(\chi, \lambda) \times u \times \dot{u} \times d \lambda \times d \chi\right)
\end{aligned}
$$

where ()$=\partial() / \partial t$ and $K_{w}, K_{u}, C_{w}, C_{u}$, are the constraint elastic and viscous parameters respectively. It is assumed that the state unknown solution variables of Equation (18) satisfy:

$$
X_{r}(\chi, t)=\alpha_{r}(\chi) \times \delta_{r}(t), \quad r=1,2,3
$$

and generally unknown functions $\alpha_{r}$ are restricted to a set of known harmonic functions:

$$
\mathbf{X}(\chi, t)=\left\{\begin{array}{lll}
a & w & d
\end{array}\right\}^{T}=\mathbf{\Psi}(\chi) \times \boldsymbol{\delta}(t)=\left[\begin{array}{ccc}
\mathbf{\Psi}_{a} & 0 & 0 \\
0 & \mathbf{\Psi}_{w} & 0 \\
0 & 0 & \mathbf{\Psi}_{d}
\end{array}\right] \times \boldsymbol{\delta}
$$

$\mathbf{\Psi}_{a}=\sqrt{2} \times\left[\begin{array}{llllll}\frac{1}{\sqrt{2}} & \sin (\pi \times \chi) & \cos (\pi \times \chi) & \ldots & \sin \left(n_{a} \times \pi \times \chi\right) & \cos \left(n_{a} \times \pi \times \chi\right)\end{array}\right]$

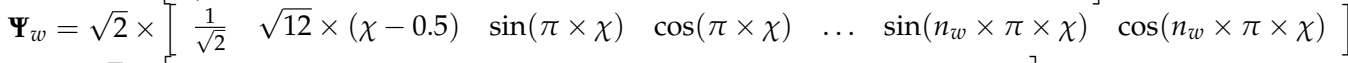

$\Psi_{d}=\sqrt{2} \times\left[\begin{array}{lllll}\sin (\pi \times \chi) & \cos (\pi \times \chi) & \ldots & \sin \left(n_{d} \times \pi \times \chi\right) & \cos \left(n_{d} \times \pi \times \chi\right)\end{array}\right]$

$\mathcal{\delta}=\left[\begin{array}{lll}\delta_{1} & \ldots & \delta_{n}\end{array}\right]^{T}, \quad n=2 \times\left(n_{a}+n_{w}+n_{d}\right)+3$

And using Equations (23) and (27):

$$
\begin{aligned}
& w=\left[\begin{array}{ccc}
\mathbf{0} & \mathbf{\Psi}_{w} & \mathbf{0}
\end{array}\right] \times \boldsymbol{\delta}, \quad u=\mathbf{B}^{T}(\lambda) \times \mathbf{\Psi}_{\mathbf{1}} \times \boldsymbol{\delta}, \\
& \varepsilon=\frac{h}{L} \times \mathbf{B}^{T}(\lambda) \times \mathbf{\Psi}_{\mathbf{2}} \times \boldsymbol{\delta}, \quad \gamma=\frac{\partial \theta(\lambda)}{\partial \lambda} \times\left[\begin{array}{ccc}
\mathbf{0} & \mathbf{0} & \mathbf{0} \\
\mathbf{0} & \mathbf{0} & \mathbf{0} \\
\mathbf{0} & \mathbf{0} & \mathbf{\Psi}_{d}
\end{array}\right] \times \boldsymbol{\delta}
\end{aligned}
$$

where:

$$
\mathbf{B}(\lambda)=\left[\begin{array}{c}
1 \\
-\lambda \\
\theta(\lambda)
\end{array}\right], \quad \mathbf{\Psi}_{\mathbf{1}}=\left[\begin{array}{ccc}
\mathbf{\Psi}_{a} & 0 & 0 \\
0 & \mathbf{\Psi}_{w}^{\prime} & 0 \\
0 & 0 & \mathbf{\Psi}_{d}
\end{array}\right], \quad \mathbf{\Psi}_{\mathbf{2}}=\left[\begin{array}{ccc}
\mathbf{\Psi}_{a}^{\prime} & 0 & 0 \\
0 & \mathbf{\Psi}_{w}^{\prime \prime} & 0 \\
0 & 0 & \mathbf{\Psi}_{d}^{\prime}
\end{array}\right]
$$

Using Equations (26)-(29), from Equations (21)-(24) results:

$$
\begin{aligned}
& U=\frac{1}{2} \times \mathcal{\delta}^{T} \times\left(\mathbf{K}_{\varepsilon}+\mathbf{K}_{\gamma}\right) \times \boldsymbol{\delta}, \\
& \mathbf{K}_{\varepsilon}=\frac{V \times h^{2}}{L^{2}} \times \int_{0}^{1} \mathbf{\Psi}_{\mathbf{2}}^{T} \times \mathbf{B}_{E} \times \mathbf{\Psi}_{\mathbf{2}} \times d \chi, \quad \mathbf{K}_{\gamma}=V \times \sum_{i=1}^{N} G_{i} \times \int_{\lambda_{i-1}}^{\lambda_{i}}\left(\frac{\partial \theta(\lambda)}{\partial \lambda}\right)^{2} \times d \lambda \times\left[\begin{array}{ccc}
\mathbf{0} & \mathbf{0} & \mathbf{0} \\
\mathbf{0} & \mathbf{0} & \mathbf{0} \\
\mathbf{0} & \mathbf{0} & \widetilde{\mathbf{\Psi}}_{d}
\end{array}\right], \\
& \mathbf{B}_{E}=\sum_{i=1}^{N} E_{i} \times \int_{\lambda_{i-1}}^{\lambda_{i}} \mathbf{B}(\lambda) \times \mathbf{B}^{T}(\lambda) \times d \lambda, \quad \widetilde{\mathbf{\Psi}}_{d}=\int_{0}^{1} \mathbf{\Psi}_{d}^{T}(\chi) \times \mathbf{\Psi}_{d}(\chi) \times d \chi \\
& W_{I}=\boldsymbol{\delta}^{T} \times\left(\mathbf{M}_{u}+\mathbf{M}_{w}\right) \times \ddot{\boldsymbol{\delta}}, \\
& \mathbf{M}_{u}=V \times h^{2} \times \int_{0}^{1} \mathbf{\Psi}_{\mathbf{1}}{ }^{T} \times \mathbf{B}_{\rho} \times \mathbf{\Psi}_{\mathbf{1}} \times d \chi, \quad \mathbf{M}_{w}=V \times L^{2} \times\left(\sum_{i=1}^{N} \rho_{i} \times\left(\lambda_{i}-\lambda_{i-1}\right)\right) \times\left[\begin{array}{ccc}
\mathbf{0} & \mathbf{0} & \mathbf{0} \\
\mathbf{0} & \widetilde{\mathbf{\Psi}}_{w} & \mathbf{0} \\
\mathbf{0} & \mathbf{0} & \mathbf{0}
\end{array}\right] \\
& \mathbf{B}_{\rho}=\sum_{i=1}^{N} \rho_{i} \times \int_{\lambda_{i-1}}^{\lambda_{i}} \mathbf{B}(\lambda) \times \mathbf{B}^{T}(\lambda) \times d \lambda, \quad \widetilde{\mathbf{\Psi}}_{w}=\int_{0}^{1} \mathbf{\Psi}_{w}^{T}(\chi) \times \mathbf{\Psi}_{w}(\chi) \times d \chi
\end{aligned}
$$




$$
\begin{aligned}
& W_{E}=-\boldsymbol{\delta}^{T} \times \mathbf{Q}, \quad \mathbf{Q}=L \times\left(Q \times\left\{\begin{array}{c}
\mathbf{0} \\
\mathbf{\Psi}_{w}^{T}(\bar{\chi}) \\
\mathbf{0}
\end{array}\right\}+L \times g \times \int_{\chi_{1}}^{\chi_{2}} q(\chi) \times\left\{\begin{array}{c}
\mathbf{0} \\
\mathbf{\Psi}_{w}^{T}(\chi) \\
\mathbf{0}
\end{array}\right\} \times d \chi\right) \\
& \Delta \prod_{e}=\frac{1}{2} \times \boldsymbol{\delta}^{T} \times\left(\Delta \mathbf{K}_{W}+\Delta \mathbf{K}_{u}\right) \times \boldsymbol{\delta} \\
& \Delta \mathbf{K}_{W}=\left[\begin{array}{ccc}
\mathbf{0} & \mathbf{0} & \mathbf{0} \\
\mathbf{0} & V \times L^{2} \times \widetilde{\mathbf{\Psi}}_{e} & \mathbf{0} \\
\mathbf{0} & \mathbf{0} & \mathbf{0}
\end{array}\right], \quad \boldsymbol{\Delta} \mathbf{K}_{u}=V \times h^{2} \times \int_{0}^{1} \mathbf{\Psi}_{\mathbf{1}}^{T}(\chi) \times \mathbf{B}_{e} \times \mathbf{\Psi}_{\mathbf{1}}(\chi) \times d \chi \\
& \mathbf{B}_{e}=\sum_{i=1}^{N} K_{u}(\chi) \times \int_{\lambda_{i-1}}^{\lambda_{i}} \mathbf{B}(\lambda) \times \mathbf{B}^{T}(\lambda) \times d \lambda, \quad \widetilde{\mathbf{\Psi}}_{e}=\int_{0}^{1} K_{w}(\chi) \times \mathbf{\Psi}_{w}^{T}(\chi) \times \mathbf{\Psi}_{w}(\chi) \times d \chi \\
& \Delta \prod_{v}=\delta^{T} \times\left(\Delta \mathbf{C}_{w}+\Delta \mathbf{C}_{u}\right) \times \dot{\delta} \\
& \Delta \mathbf{C}_{w}=\left[\begin{array}{ccc}
\mathbf{0} & \mathbf{0} & \mathbf{0} \\
\mathbf{0} & V \times L^{2} \times \widetilde{\mathbf{\Psi}}_{v} & \mathbf{0} \\
\mathbf{0} & \mathbf{0} & \mathbf{0}
\end{array}\right], \quad \Delta \mathbf{K}_{u}=V \times h^{2} \times \int_{0}^{1} \boldsymbol{\Psi}_{\mathbf{1}}^{T}(\chi) \times \mathbf{B}_{v} \times \mathbf{\Psi}_{\mathbf{1}}(\chi) \times d \chi \\
& \mathbf{B}_{v}=\sum_{i=1}^{N} C_{u}(\chi) \times \int_{\lambda_{i-1}}^{\lambda_{i}} \mathbf{B}(\lambda) \times \mathbf{B}^{T}(\lambda) \times d \lambda, \quad \widetilde{\mathbf{\Psi}}_{v}=\int_{0}^{1} C_{w}(\chi) \times \mathbf{\Psi}_{w}^{T}(\chi) \times \mathbf{\Psi}_{w}(\chi) \times d \chi
\end{aligned}
$$

and the resulting equation of motion is:

$$
\left(\mathbf{M}_{u}+\mathbf{M}_{w}\right) \times \ddot{\boldsymbol{\delta}}+\left(\Delta \mathbf{C}_{w}+\Delta \mathbf{C}_{u}\right) \times \dot{\delta}+\left[\left(\mathbf{K}_{\varepsilon}+\mathbf{K}_{\gamma}\right)+\left(\Delta \mathbf{K}_{w}+\Delta \mathbf{K}_{u}\right)\right] \times \boldsymbol{\delta}=\mathbf{Q} .
$$

Because of the elasto-hysteretic assumption (Equation (15)), complex $\mathbf{M}_{u}, \Delta \mathbf{C}_{u}, \mathbf{K}_{\varepsilon}, \Delta \mathbf{K}_{u}$ matrices result. To find the beam frequency response function $\widetilde{F}\left(\chi_{w}, \chi_{q}, j \omega\right)$, i.e., the complex transverse response $\widetilde{w}\left(\chi_{w}, j \omega\right)$ related to unitary, lumped, harmonic excitation at frequency $\omega$ applied at abscissa $\chi_{q}$, the following procedure is applied. Both sides of Equation (35) are Fourier transformed $F()=(\hat{)})$

$$
\left[-\omega^{2} \times\left(\mathbf{M}_{u}+\mathbf{M}_{w}\right)+j \times \omega \times\left(\Delta \mathbf{C}_{w}+\Delta \mathbf{C}_{u}\right)+\left(\mathbf{K}_{\varepsilon}+\mathbf{K}_{\gamma}\right)+\left(\Delta \mathbf{K}_{w}+\Delta \mathbf{K}_{u}\right)\right] \times \hat{\boldsymbol{\delta}}=\hat{\mathbf{Q}} .
$$

The frequency response function matrix $\mathbf{F}(j \omega)$ is:

$$
\mathbf{F}(j \times \omega)=\left[-\omega^{2} \times\left(\mathbf{M}_{u}+\mathbf{M}_{w}\right)+j \times \omega \times\left(\Delta \mathbf{C}_{w}+\Delta \mathbf{C}_{u}\right)+\left(\mathbf{K}_{\varepsilon}+\mathbf{K}_{\gamma}\right)+\left(\Delta \mathbf{K}_{w}+\Delta \mathbf{K}_{u}\right)\right]^{-1} .
$$

Equation (37) can be expressed as:

$$
\begin{aligned}
& \mathbf{F}(j \times \omega)=[\mathbf{O}(j \times \omega)+\Delta \mathbf{O}(j \times \omega)]^{-1} \\
& \mathbf{O}(j \times \omega)=-\omega^{2} \times \operatorname{Re}\left(\mathbf{M}_{u}+\mathbf{M}_{w}\right)+j \times \omega \times \operatorname{Re}\left(\Delta \mathbf{C}_{w}+\Delta \mathbf{C}_{u}\right)+\operatorname{Re}\left(\left(\mathbf{K}_{\varepsilon}+\mathbf{K}_{\tau}\right)+\left(\Delta \mathbf{K}_{w}+\Delta \mathbf{K}_{u}\right)\right) \\
& \boldsymbol{\Delta} \mathbf{O}(j \times \omega)=-\omega^{2} \times j \times \operatorname{Im}\left(\mathbf{M}_{u}+\mathbf{M}_{w}\right)-\omega \times \operatorname{Im}\left(\Delta \mathbf{C}_{w}+\Delta \mathbf{C}_{u}\right)+j \times \operatorname{Im}\left(\left(\mathbf{K}_{\varepsilon}+\mathbf{K}_{\gamma}\right)+\left(\Delta \mathbf{K}_{w}+\Delta \mathbf{K}_{u}\right)\right)
\end{aligned}
$$

And from Equation (38):

$$
(\mathbf{O}+\Delta \mathbf{O}) \times \mathbf{F}=\mathbf{I}
$$

Pre-multiplying both sides of Equation (39) by $\mathbf{F}_{0}=\mathbf{O}^{-1}$ :

$$
\mathbf{F}_{0} \times(\mathbf{O}+\Delta \mathbf{O}) \times \mathbf{F}=\mathbf{F}_{0} .
$$

With further manipulation of Equation (40):

$$
\mathbf{F}=\left(\mathbf{I}+\mathbf{F}_{0} \times \Delta \mathbf{O}\right)^{-1} \times \mathbf{F}_{0} .
$$


In Equation (41) $\mathbf{F}_{0}$ can be expressed in closed form by means of modal decomposition [45]. The beam frequency response function is:

$$
\widetilde{F}\left(\chi_{w}, \chi_{q}, j \omega\right)=\left[\begin{array}{lll}
\mathbf{0} & \mathbf{\Psi}_{w}\left(\chi_{w}\right) & \mathbf{0}
\end{array}\right] \times \mathbf{F}(j \cdot \omega) \times\left[\begin{array}{lll}
\mathbf{0} & \mathbf{\Psi}_{w}\left(\chi_{q}\right) & \mathbf{0}
\end{array}\right]^{T}
$$

Evaluation of $\widetilde{F}\left(\chi_{w}, \chi_{q}, j \omega\right)$ makes it possible to virtually estimate the damping behaviour of the beam under study, i.e., by using the previously defined function $z(j \omega)$ or by defining a new damping estimator $r\left(\chi_{w}, \chi_{q}, j \omega\right)=\left|\operatorname{Im}\left(\widetilde{F}\left(\chi_{w}, \chi_{q}, j \omega\right)\right)\right| /\left|\widetilde{F}\left(\chi_{w}, \chi_{q}, j \omega\right)\right|$, where $r \in \Re, \quad r \in[0,1]$.

\subsection{Model Application Examples}

Two different beam architectures are presented as examples, B1 and B2. Their data are reported in Table 3 where $h_{i}$ is the thickness of the $i$-th beam layer. For both the examples $L=1.1 \mathrm{~m}$ and $g=0.08 \mathrm{~m}$. The number of layers are $N=3$ (B1) and $N=7$ (B2). The constant parameters $K_{u}^{\prime}, K_{w}^{\prime}, C_{u}^{\prime}, C_{w}^{\prime}$ take into account the beam distributed viscoelastic boundary conditions (clamped-free) and are applied at $0 \leq \chi \leq 0.09$. Constant parameters $C_{u}^{\prime \prime}$ and $C_{w}^{\prime \prime}$ are used to define uniformly distributed viscous actions $(0 \leq \chi \leq 1)$ that model the system inherent damping.

Table 3. Beam model data.

\begin{tabular}{|c|c|c|c|c|c|c|}
\hline \multicolumn{7}{|c|}{ Beam Layer Data } \\
\hline Beam & $h_{i}(\mathrm{~mm})$ & $E_{i}(\mathrm{GPa})$ & \multicolumn{2}{|c|}{$G_{i}(\mathrm{GPa})$} & \multicolumn{2}{|c|}{$\rho_{i}\left(10^{3} \mathrm{~kg} / \mathrm{m}^{3}\right)$} \\
\hline B1 & $\{25,50,25\}$ & \multirow{2}{*}{$\begin{array}{c}\{9,210,9\} \\
\{9,210,9,210,9,210,9\}\end{array}$} & \multirow{2}{*}{\multicolumn{2}{|c|}{$\begin{array}{c}\{3.5,80,3.5\} \\
\{3.5,80,3.5,80,3.5,80,3.5\}\end{array}$}} & \multirow{2}{*}{\multicolumn{2}{|c|}{$\begin{array}{c}\{1.9,7.85,1.9\} \\
\{1.9,7.85,1.9,7.85,1.9,7.85,1.9\}\end{array}$}} \\
\hline B2 & $\{10,5,10,50,10,5,10\}$ & & & & & \\
\hline \multicolumn{7}{|c|}{ Constrain Parameters } \\
\hline Beam & $K_{w}^{\prime}\left(10^{15} \mathrm{~N} / \mathrm{m}^{4}\right)$ & $K_{u}^{\prime}\left(10^{15} \mathrm{~N} / \mathrm{m}^{4}\right)$ & $\begin{array}{c}C_{w}^{\prime} \\
\left(10^{5} \mathrm{~N} \cdot \mathrm{s} / \mathrm{m}^{4}\right)\end{array}$ & $\begin{array}{c}C_{u}^{\prime} \\
\left(10^{5} \mathrm{~N} \cdot \mathrm{s} / \mathrm{m}^{4}\right)\end{array}$ & $\begin{array}{c}C_{w}^{\prime \prime} \\
\left(10^{5} \mathrm{~N} \cdot \mathrm{s} / \mathrm{m}^{4}\right)\end{array}$ & $\begin{array}{c}\mathrm{C}_{u}^{\prime \prime} \\
\left(10^{5} \mathrm{~N} \cdot \mathrm{s} / \mathrm{m}^{4}\right)\end{array}$ \\
\hline B1 & 1 & 10 & 8 & 2 & 1.2 & 0.01 \\
\hline B2 & 1 & 10 & 8 & 2 & 1.4 & 0.2 \\
\hline \multicolumn{7}{|c|}{ Interface Parameters } \\
\hline Beam & \multicolumn{2}{|c|}{$\varphi_{i}\left(10^{8} \mathrm{~N} / \mathrm{m}^{3}\right)$} & \multicolumn{4}{|c|}{$\eta_{i}\left(10^{10} \mathrm{~N} / \mathrm{m}^{3}\right)$} \\
\hline $\begin{array}{l}\text { B1 } \\
\text { B2 }\end{array}$ & \multicolumn{2}{|c|}{$\begin{array}{c}\{6,6\} \\
\{8,8,8,8,8,8\}\end{array}$} & \multicolumn{4}{|c|}{$\begin{array}{c}\{3,3\} \\
\{5,5,5,5,5,5\}\end{array}$} \\
\hline
\end{tabular}

The effect of introducing hysteretic dissipative actions at the layer interfaces can be observed by comparing the results reported in Figures 12 and 13. The real, the imaginary part of the inertance $\left(\operatorname{In}\left(\chi_{w}, \chi_{q}, j \omega\right)=-\omega^{2} \times \widetilde{F}\left(\chi_{w}, \chi_{q}, j \omega\right)\right)$ frequency response function (FRF), calculated at $\chi_{w}=1$ and $\chi_{q}=1$, and the damping estimator $r(j w)$ are plotted.
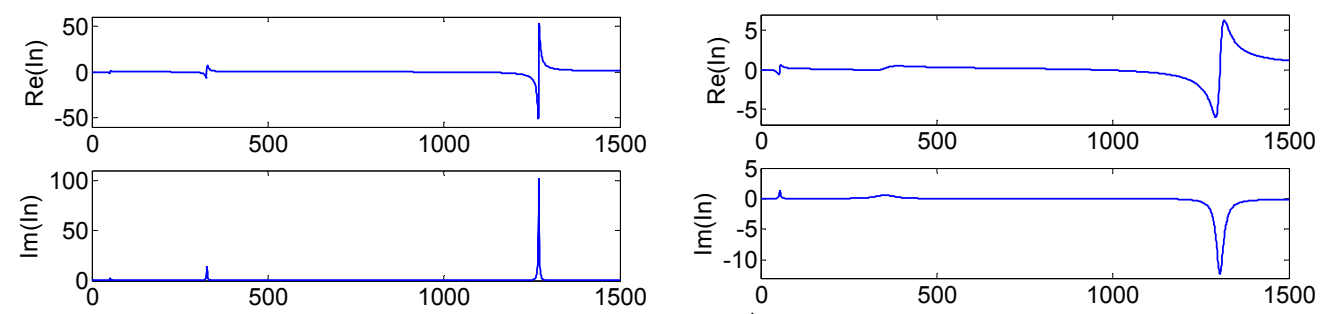

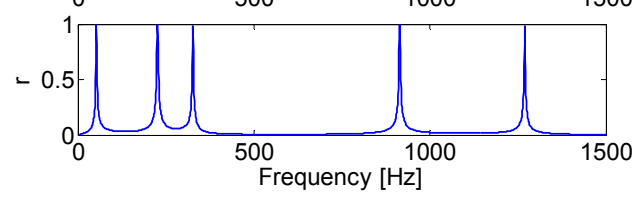

(a)

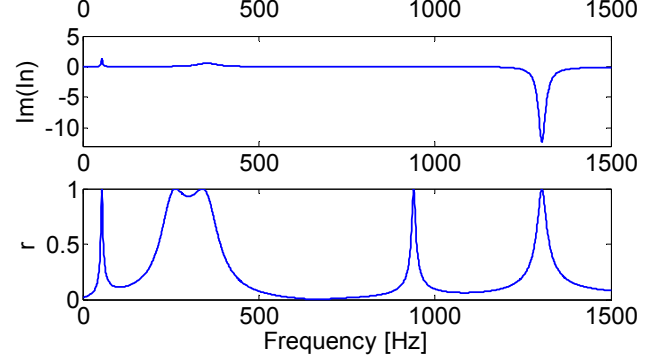

(b)

Figure 12. Inertance $(\operatorname{In}(1,1, j \omega))$ real and imaginary part, and $r(j \omega)$ for beam $\mathrm{B} 1_{0}(\mathbf{a})$ and $\mathrm{B} 1(\mathbf{b})$. 


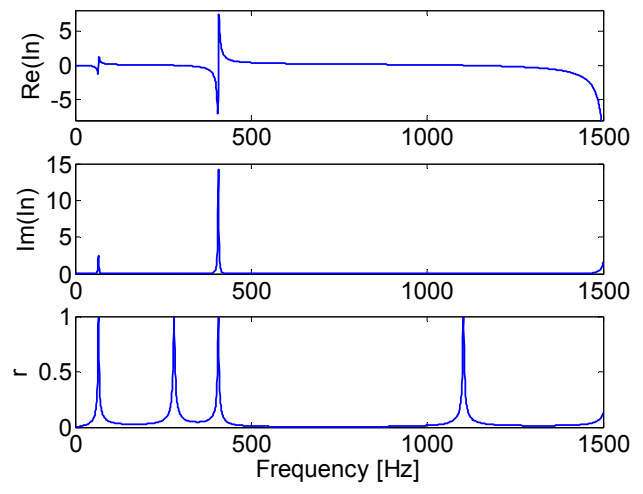

(a)

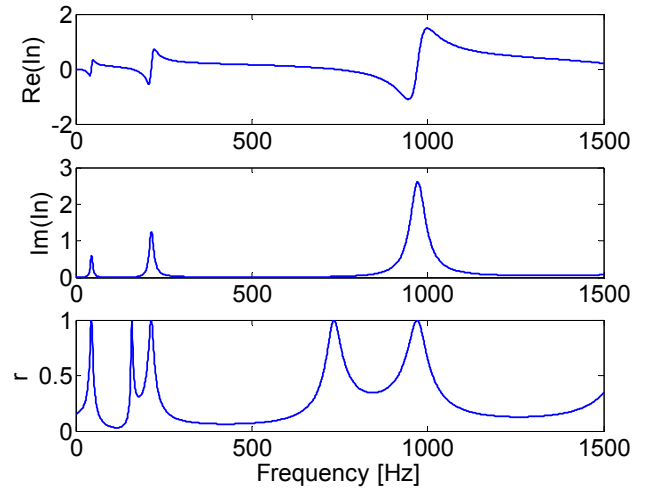

(b)

Figure 13. Inertance $(\operatorname{In}(1,1, j \omega))$ real and imaginary part, and $r(j \omega)$ for beam $\mathrm{B} 2_{0}(\mathbf{a})$ and $\mathrm{B} 2(\mathbf{b})$.

Figures 12a and 13a show the results for beams $\mathrm{B} 1_{0}$ and $\mathrm{B} 2_{0}$ respectively, when no slipping occurs $\left(\varphi_{i}=10^{16} \mathrm{~N} / \mathrm{m}^{3}, \eta_{i}=0, \forall i\right)$, Figures $12 \mathrm{~b}$ and $13 \mathrm{~b}$ show the results for beams B1 and B2 respectively, taking into account of interface slipping and hysteretic dissipation. Table 4 reports B1, B1 $1_{0}, \mathrm{~B} 2, \mathrm{~B} 2_{0}$ natural frequencies and damping ratios. B1 and B2 damping ratios are estimated by means of the Single Degree of Freedom (SDOF) circle fit method [45], while $\mathrm{B} 1_{0}$ and $\mathrm{B} 2_{0}$ damping ratios are normally obtained from within the solutions of a generalized eigenvalue problem [45].

Table 4. Natural frequencies and damping ratios.

\begin{tabular}{ccccccc}
\hline \multirow{2}{*}{ Beam } & \multicolumn{3}{c}{ Natural Frequency $\mathbf{( H z )}$} & \multicolumn{3}{c}{ Damping Ratio (\%) } \\
\cline { 2 - 7 } & $\mathbf{1}$ & $\mathbf{2}$ & $\mathbf{3}$ & $\mathbf{1}$ & $\mathbf{2}$ & $\mathbf{3}$ \\
\hline $\mathrm{B} 1_{0}$ & 52.41 & 326.74 & 1269.16 & 2.32 & 0.43 & 0.109 \\
$\mathrm{~B} 1$ & 54.04 & 352.48 & 1303.83 & 4.48 & 10.3 & 0.931 \\
$\mathrm{~B} 2_{0}$ & 65.84 & 406.45 & 1291.1 & 1.95 & 0.36 & 0.0178 \\
$\mathrm{~B} 2$ & 44.64 & 214.77 & 971.34 & 8.88 & 3.6 & 2.77 \\
\hline
\end{tabular}

\section{Conclusions}

Eight different innovative composite solutions were experimentally investigated, and the results were compared; these findings were never before published. A significant increase of the damping behaviour is observed for all of these solutions with respect to the uncoated components, and also with respect to already known solutions, previously investigated by these authors and other researchers. The coating solution employing $\mathrm{Al}_{2} \mathrm{O}_{3}$ powder + matrix, made by screen printing and curing technology on $\mathrm{Al}$ alloy substrate, proved to be the most effective technology with respect to the aim of this work.

It can be outlined that the interface between substrate and coating heavily affects the effectiveness of the composite solution. Moreover, test results and comparison also outlined the influence of the substrate surface texture interface on the damped response. These results confirm the role of interface frictional actions in determining the composite damping behaviour. It should be outlined that the experimental estimate of the adhesion strength between coating and substrate can be evaluated by means of an adhesion test apparatus, and will be performed in future work.

An extended multi layered beam model was developed in order to design and optimize new, more effective coating solutions, engineered to maximize the damping contribution of frictional actions at the coating layer interfaces, or at the coating substrate interface. This model is based on high order multi-layer beam theories and takes into account of the contribution of interface frictional actions. The aim is to use the model as an experimental tool to identify the model parameters of the local dissipative actions acting at some interfaces between two different layers and as a design tool 
in order to explore new optimized coating solutions according to fixed engineering specifications. Some application examples of the model were presented. Nevertheless, experimental-numerical tools able to identify the complex elasto-hysteretic interface impedance must be developed in order to make this model suitable for engineering applications and will be presented in a future paper. Moreover, the application of this coating technology in real engineering applications, such as thin-walled components used in the automotive or automatic machine industry, should also be taken into account. Residual stresses at the interface between the coating layers and substrate may be taken into account in the multilayer beam model proposed in this work, since this contribution can be high and may be expected to play a major role in the adhesion behaviour of coated solutions when dealing with PVD based coating deposition technologies. It also appears that such extended beam models could also be used to experimentally identify this unknown residual stress field from measuring the deformed profile of a cantilever beam resulting from the application of a coated layer. Some analytical, numerical and experimental work is currently under development by our research team.

Acknowledgments: This study was developed within the CIRI-MAM with the contribution of the Regione Emilia Romagna, progetto POR Fesr Tecnopoli. Support from Andrea Zucchini and Marzocchi Pompe S.p.A., Casalecchio di Reno, Italy, is also kindly acknowledged.

Author Contributions: Stefano Amadori and Giuseppe Catania conceived, designed and performed the experiments; defined and implemented the numerical model, analyzed and critically discussed the numerical and experimental results and finally wrote the paper; Angelo Casagrande found the coating material composition, the manufacturing technology and performed the material experimental structural investigation.

Conflicts of Interest: The authors declare no conflict of interest.

\section{References}

1. Lopez de Lacalle, L.N.; Gutierrez, A.; Lamikiz, A.; Fernandes, M.H.; Sanchez, J.A. Turning of Thick Thermal Spray Coatings. J. Therm. Spray Technol. 2001, 10, 249-254. [CrossRef]

2. Fernández-Abia, A.I.; Barreiro, J.; Lopez de Lacalle, L.N.; González-Madruga, D. Effect of mechanical pre-treatments in the behavior of nanostructured PVD-coated tools in turning. Int. J. Adv. Manuf. Technol. 2014, 73, 1119-1132. [CrossRef]

3. Rodríguez-Barrero, S.; Fernández-Larrinoa, J.; Azkona, I.; López de Lacalle, L.N.; Polvorosa, R. Enhanced Performance of Nanostructured Coatings for Drilling by Droplet Elimination. Mater. Manuf. Process. 2016, 31, 593-602. [CrossRef]

4. Fernandez-Valdivielso, A.; Lopez de Lacalle, LN.; Urbikain, G.; Rodriguez, A. Detecting the key geometrical features and grades of carbide inserts for the turning of nickel-based alloys concerning surface integrity. J. Mech. Eng. Sci. 2016, 230, 3725-3742. [CrossRef]

5. Polvorosab, R.; Suáreza, A.; Lopez de Lacalle, L.N.; Cerrill, I.; Wretlandc, A.; Veigaa, F. Tool wear on nickel alloys with different coolant pressures: Comparison of Alloy 718 and Waspaloy. J. Manuf. Process. 2017, 26, 44-56. [CrossRef]

6. Elosegui, I.; Alonso, U.; Lopez de Lacalle, L.N. PVD coatings for thread tapping of austempered ductile iron. Int. J. Adv. Manuf. Technol. 2017, 91, 2663-2672. [CrossRef]

7. Ghidelli, M.; Sebastiani, M.; Collet, C.; Guillemet, R. Determination of the elasticmoduli and residual stresses of freestanding Au-TiW bilayer thin films by nanoindentation. Mater. Des. 2016, 106, 436-445. [CrossRef]

8. Nix, W.D. Mechanical properties of thin films. Metall. Trans. A 1989, 20, 2217-2245. [CrossRef]

9. Oliver, W.C.; Pharr, G.M. Measurement of hardness and elastic modulus by instrumented indentation: Advances in understanding and refinements to methodology. J. Mater. Res. 2003, 19, 3-20. [CrossRef]

10. Tassini, N.; Pastias, S.; Lambrinou, K. Ceramic coatings: A phenomenological modeling for damping behavior related to microstructural features. Mater. Sci. Eng. A 2006, 442, 509-513. [CrossRef]

11. Yu, L.; Ma, Y.; Zhou, C.; Xu, H. Damping efficiency of the coating structure. Int. J. Solids Struct. 2005, 42, 3045-3058. [CrossRef]

12. Ustinov, A.I.; Movchan, B.A. A study of damping ability of tin-and yttrium-coated flat specimens of Ti-6\%Al-4\%V titanium alloy. Strength Mater. 2001, 33, 339-343. [CrossRef] 
13. Rongong, J.A.; Goruppa, A.A.; Buravalla, V.R.; Tomlinson, G.R.; Jones, F.R. Plasma deposition of constrained layer damping coating. J. Mech. Eng. Sci. 2004, 218, 669-680. [CrossRef]

14. Blackwell, C.; Palazzotto, A.; George, T.J.; Cross, C.J. The evaluation of the damping characteristics of hard coating on titanium. Shock Vib. 2007, 14, 37-51. [CrossRef]

15. Casadei, F.; Bertoldi, K.; Clarke, D.R. Vibration damping of thermal barrier coatings containing ductile metallic layers. ASME J. Appl. Mech. 2014, 81, 101001. [CrossRef]

16. Du, G.; Tan, Z.; Ba, D.; Liu, K.; Sun, W.; Han, Q. Damping properties of a novel porous Mg-Al alloy coating prepared by arc ion plating. Surf. Coat. Technol. 2014, 238, 139-142. [CrossRef]

17. Ustinov, A.I.; Skorodzievskii, V.S. A study of the dissipative properties of homogeneous materials deposited as coatings part 2. Copper condensates with different microstructural characteristics. Strength Mater. 2008, 40, 275-277. [CrossRef]

18. Colorado, H.A.; Velez, J.; Salva, H.R.; Ghilarducci, A.A. Damping behavior of physical vapor-deposited TiN coatings on AISI 304 stainless steel and adhesion determination. Mater. Sci. Eng. A 2006, 442, 514-518. [CrossRef]

19. Khor, K.A.; Chia, C.T.; Gu, Y.W.; Boey, F.Y.C. High temperature damping behavior of plasma sprayed NiCoCrAlY coatings. J. Therm. Spray Technol. 2002, 11, 359-364. [CrossRef]

20. Wang, X.; Pei, Y.; Ma, Y. The effect of microstructure at interface between coating and substrate on damping capacity of coating systems. Appl. Surf. Sci. 2013, 282, 60-66. [CrossRef]

21. Kiretseu, M.; Hui, D.; Tomlinson, G. Advanced shock-resistant and vibration damping of nanoparticle-reinforced composite material. Compos. Part B 2008, 39, 128-138. [CrossRef]

22. Amadori, S.; Catania, G. Damping contributions of coatings to the viscoelastic behaviour of mechanical components. In Proceedings of the Surveillance 9 International Conference, Fez, Morocco, 22-24 May 2017; pp. 1-13.

23. Amadori, S.; Catania, G. Experimental evaluation of the damping properties and optimal modeling of coatings made by plasma-deposition techniques. In Proceedings of the 7th International Conference on Mechanics and Materials in Design Albufeira, Algarve, Portugal, 11-15 June 2017; INEGI/FEUP: Porto, Portugal, 2017; pp. 313-324.

24. Buravalla, V.R.; Remillat, C.; Rongrong, J.A.; Tomlinson, G.A. Advances in damping materials and technology. Smart Mater. Bull. 2001, 8, 10-13. [CrossRef]

25. Reed, S.A.; Palazzotto, A.N.; Baker, W.P. An experimental technique for the evaluation of strain dependent material properties of hard coatings. Shock Vib. 2008, 15, 697712. [CrossRef]

26. Pastias, S.; Saxton, C.; Shipton, M. Hard damping coatings: An experimental procedure for extraction of damping characteristics and modulus of elasticity. Mater. Sci. Eng. A 2004, 370, 412-416. [CrossRef]

27. Torvik, P.J. Determination of mechanical properties of non-linear coatings from measurements with coated beams. Int. J. Solids Struct. 2009, 46, 1066-1077. [CrossRef]

28. Averill, R.C.; Yip, Y.C. Development of simple robust finite elements based on refined theories for thick laminated beams. Comput. Struct. 1996, 59, 529546. [CrossRef]

29. Di Sciuva, M.; Gherlone, M.; Librescu, L. Implications of damaged interfaces and of other non-classical effects on the load carrying capacity of multilayered composite shallow shells. Int. J. Non-Linear Mech. 2002, 37, 851-867. [CrossRef]

30. Iurlaro, L.; Gherlone, M.; di Sciuva, M.; Tessler, A. Refined Zigzag Theory for laminated composite and sandwich plated derived from Reissner's Mixed Variational Theorem. Compos. Struct. 2015, 133, 809-817. [CrossRef]

31. Liu, D.; Li, X. An overall view of laminate theories based on the displacement hypothesis. J. Compos. Mater. 1996, 30, 1539-1561. [CrossRef]

32. Yong, S.L.; Feng, D.W.; Lukey, G.C.; van Deventer, J.S.J. Chemical characterization of the steel-geopolymeric gel interface. Colloids Surf. A Physicochem. Eng. Asp. 2007, 302, 411-423. [CrossRef]

33. Prud'Homme, E.; Michaud, P.; Joussein, E.; Clacens, J.; Arii-Clacens, S.; Sobrados, I.; Peyratout, C.; Smith, A.; Sanz, J.; Rossignol, S. Structural characterization of geomaterial foams-Thermal behavior. J. Non-Cryst. Solids 2011, 357, 3637-3647. [CrossRef]

34. Temuujin, J.; Minjihmaa, A.; Rickard, W.; Lee, M.; Williams, I.; van Riessen, A. Preparation of metacaolin based geopolymer coatings on metal substrates as thermal barriers. Appl. Clay Sci. 2009, 46, 265-270. [CrossRef] 
35. He, J.; Zhang, J.; Yu, Y.; Zhang, G. The strength and microstructure of two geopolymers derived from metakaolin and red mud-fly ash admixture: A comparative study. Constr. Build. Mater. 2012, 30, 80-91. [CrossRef]

36. Rovnaník, P. Effect of curing temperature on the development of hard structure of metakaolin-based geopolymer. Constr. Build. Mater. 2010, 24, 1176-1183. [CrossRef]

37. Amadori, S.; Catania, G. Robust identification of the mechanical properties of viscoelatic non-standard materials by means of time and frequency domain experimental measurements. Compos. Struct. 2017, 169, 79-89. [CrossRef]

38. Nowick, A.S.; Berry, B.S. Anelastic Relaxation in Crystalline Solids; Academic Press Inc.: Cambridge, MA, USA, 1972.

39. Di Sciuva, M. Multilayered anisotropic plate models with continuous interlaminar stresses. Compos. Struct. 1992, 22, 149-167. [CrossRef]

40. Librescu, L.; Schmidt, R. A general linear theory of laminated composite shells featuring interlaminar bonding imperfections. Int. J. Solid Struct. 2001, 38, 3355-3375. [CrossRef]

41. Reddy, J.N. On refined theories of composite laminates. Meccanica 1990, 25, 230-238. [CrossRef]

42. Sun, C.T.; Whitney, J.M. Theory for the Dynamic Response of Laminated Plates. AIAA J. 1973, 11, $178-183$. [CrossRef]

43. Sun, W.; Liu, Y.; Du, G. Analytical Modeling of Hard-Coating Cantilever Composite Plate considering the Material Nonlinearity of Hard Coating. Math. Probl. Eng. 2015, 2015, 978392. [CrossRef]

44. Wang, G.; Unal, A.; Zuo, Q.H. Modelling and Analysis of Multilayered Elastic Beam Using Spectral Finite Element Method. J. Vib. Acoust. 2016, 138, 041013. [CrossRef]

45. Ewins, D.J. Modal Testing: Theory, Practice and Applications, 2nd ed.; Research Studies Press, University of Michigan: Ann Arbor, MI, USA, 2000.

(C) 2018 by the authors. Licensee MDPI, Basel, Switzerland. This article is an open access article distributed under the terms and conditions of the Creative Commons Attribution (CC BY) license (http:/ / creativecommons.org/licenses/by/4.0/). 